Article

\title{
Effect of Climate Change on Maize Yield in the Growing Season: A Case Study of the Songliao Plain Maize Belt
}

\author{
Ari Guna ${ }^{1,2,3}$, Jiquan Zhang ${ }^{1,2,3, * \mathbb{C}}$, Siqin Tong ${ }^{1,2}$, Yongbin Bao ${ }^{1}$, Aru Han ${ }^{1}$ and Kaiwei Li ${ }^{1}$ \\ 1 School of Environment, Northeast Normal University, No.2555 Jingyue Street, Nanguan, Changchun 130117, \\ China; argn078@nenu.edu.cn (A.G.); tongsq223@nenu.edu.cn (S.T.); baoyb924@nenu.edu.cn (Y.B.); \\ arh690@nenu.edu.cn (A.H.); likw395@nenu.edu.cn (K.L.) \\ 2 State Environmental Protection Key Laboratory of Wetland Ecology and Vegetation Restoration, \\ Northeast Normal University, No.2555 Jingyue Street, Nanguan, Changchun 130117, China \\ 3 Key Laboratory for Vegetation Ecology, Ministry of Education, No.2555 Jingyue Street, Nanguan, \\ Changchun 130117, China \\ * Correspondence: zhangjq022@nenu.edu.cn; Tel.: +86-0431-8916-5616
}

Received: 31 August 2019; Accepted: 6 October 2019; Published: 10 October 2019

\begin{abstract}
Based on the 1965-2017 climate data of 18 meteorological stations in the Songliao Plain maize belt, the Coupled Model Intercomparision Project (CMIP5) data, and the 1998-2017 maize yield data, the drought change characteristics in the study area were analyzed by using the standardized precipitation evapotranspiration index (SPEI) and the Mann-Kendall mutation test; furthermore, the relationship between meteorological factors, drought index, and maize climate yield was determined. Finally, the maize climate yields under $1.5^{\circ} \mathrm{C}$ and $2.0^{\circ} \mathrm{C}$ global warming scenarios were predicted. The results revealed that: (1) from 1965 to 2017, the study area experienced increasing temperature, decreasing precipitation, and intensifying drought trends; (2) the yield of the study area showed a downward trend from 1998 to 2017. Furthermore, the climate yield was negatively correlated with temperature, positively correlated with precipitation, and positively correlated with SPEI- 1 and SPEI-3; and (3) under the $1.5^{\circ} \mathrm{C}$ and the $2.0^{\circ} \mathrm{C}$ global warming scenarios, the temperature and the precipitation increased in the maize growing season. Furthermore, under the studied global warming scenarios, the yield changes predicted by multiple regression were $-7.7 \%$ and $-15.9 \%$, respectively, and the yield changes predicted by one-variable regression were $-12.2 \%$ and $-21.8 \%$, respectively.
\end{abstract}

Keywords: drought; global warming; maize yield; Songliao Plain maize belt

\section{Introduction}

The agriculture sector is closely linked to sustainability and food security, as at least 159 million people, $2.19 \%$ of the world population, are directly or indirectly dependent on crop production; however, the agriculture sector is extremely vulnerable to climate-induced risks and natural disasters [1]. The Fourth Assessment Report of the Intergovernmental Panel on Climate Change (IPCC.AR4) [2] points out that the earth has experienced significant changes characterized by global warming in the past 100 years. To avoid possible harm to the ecological environment caused by global warming, The Paris Agreement explicitly proposes controlling the global temperature rise within $2.0^{\circ} \mathrm{C}$ and within $1.5^{\circ} \mathrm{C}$ above the industrial level [3]. Unstable global climate change will lead to an increase or a decrease in the instability of agricultural production [4,5]. Drought formation is due not only to numerous natural environments but also to human interventions. In the field of agriculture, inappropriate temperature, precipitation, humidity, and other conditions in the key growth period of crops eventually lead to yield changes. The abundance of grain production will directly affect national 
food security. Maize is the most important crop in northeast China. Drought is mainly distributed in northeast, north, and northwest China [6]. Owing to the impact of drought disasters, the production and the price of foreign maize trade circulation and other fields have undergone significant changes. The risk of unstable maize production caused by drought persists; it will directly affect the world maize trade circulation pattern and poses a serious threat to global food security. Therefore, it is necessary to explore and evaluate climate change and drought disasters and further study their impact on crop yield. Based on the literature at home and abroad, the impacts of climate variability and change on crop yields have been studied by numerous researchers worldwide both for historical and future climates and for various crops $[7,8]$.

Presently, there are three main methods for studying the impact of climate change on grain crop yield: the field test method, which can be used to find the correlation between climate change characteristics and farmland crop management practices and the impact of climate change on agricultural production, the global climate model (GCM), and the regional climate model (RegCM), as well as other predictions of different climate change scenarios on crop yield [4] or by adding meteorological variables to the production function model [9]. Among them, Coupled Model Intercomparision Project (CMIP5) introduces the earth system model and its biogeochemical process, enabling realization of the global carbon cycle process and the dynamic preparation process, the use of statistical data to establish a correlation matrix between meteorological factors and crop yield, quantitative analysis of crop yield to climate change law, and response [7]. For example, some studies reported reductions in wheat yields in France and maize yields in China as a result of increased temperature $[10,11]$. In the United States, the yield impacts on maize, wheat, and soybean are not obvious owing to the less significant climate trends [12]. Gupta et al. [13] used the method of combining the GCM and a crop model to predict the change in rice yield in India. Chen et al. [14] calculated the linear trend of time and found that an increase in temperature increased the national single-season rice yield by $11 \%$.

Future climate change research on crop yield focuses on the climate change background of global temperature rises of $1.5^{\circ} \mathrm{C}$ and $2.0^{\circ} \mathrm{C}$. Huang et al. [15] showed that the global warming in arid and semi-arid regions has been $20-40 \%$ higher than in humid regions in the past 100 years. When the average global warming in the future reaches $2.0^{\circ} \mathrm{C}$, climate disasters such as maize yield reduction, surface runoff reduction, drought intensification, and malaria transmission caused by an increase in temperature will be the most serious in arid and semi-arid regions. Under the background of global warming, the yields of rice and maize have been reduced by $10 \%$ and $3.8 \%$, respectively [16,17]. Chen et al. [18] mainly discussed the distribution characteristics of the main crop yields in China and analyzed the spatial variation characteristics of flowering period, maturity period, yield, evapotranspiration (ET), and water use efficiency (WUE) of maize in China's maize planting areas under the $1.5^{\circ} \mathrm{C}$ and the $2.0^{\circ} \mathrm{C}$ global warming scenarios .

The above research is mainly based on meteorological factors. In fact, as drought indices are related to the cumulative effects of a prolonged and abnormal moisture deficiency, they have a strong connection to agriculture. A number of studies related to drought analysis and monitoring have been conducted using the precipitation anomaly percentage ( $\mathrm{Pa}$ ) [19], the Palmer drought severity index (PDSI) [20], the standardized precipitation index (SPI) [21], the integrated meteorological drought index (CI) [22], the standardized precipitation evapotranspiration index (SPEI) [23], etc. For example, Zhang et al. [24], using the SPEI to describe drought situations and evaluate the relationship between drought risk and yield in each growth period, found that drought disaster in the entire growth period is closely related to maize yield. Matiu et al. [25] studied the relationship between crop yield and growth season temperature and SPEI in major maize, rice, soybean, and wheat producing countries and found that the combined effects of high temperature and drought significantly reduced the yield of maize, soybean, and wheat by $11.6 \%, 12.4 \%$, and $9.2 \%$, respectively. The SPEI combines the advantages of SPI and PDSI, taking into account the effect of evaporation on drought. It is sensitive to temperature changes and has the advantage of allowing for a convenient SPI calculation. It is suitable for multi-scale and 
multi-space comparison and can more sensitively reflect drought characteristics under the background of climate warming. In designing the SPEI computation, Vicente-Serrano et al. [23] followed the same theoretical basis that McKee et al. [21] devised to improve the SPI; moreover, the SPEI also has good applicability in China.

The Songliao Plain maize belt is the main body of the northeast industrial base, shouldering the great responsibility of food security in the country, and is also a traditional agricultural area dominated by food production. In recent decades, the climate change in the maize belt of the Songliao Plain has been remarkable, which has had an obvious impact on the maize production in this area. Fifty-five percent of the grain output reduction in the central Songliao Plain is caused by agro-meteorological disasters. Drought, which accounts for $60 \%$ of agro-meteorological disasters, occurs frequently in the central part of Songliao Plain [26]. Therefore, the aim of this study was to predict the change trend of maize yield under the $1.5^{\circ} \mathrm{C}$ and the $2.0^{\circ} \mathrm{C}$ global warming scenarios through regression equations obtained from historical climate change data and maize yield. Specifically, we (1) studied the climate change characteristics during the growing season from 1965 to 2017, i.e., temperature, precipitation, and drought characteristics SPEI, (2) established their relationship with maize yield, and (3) finally predicted the future climate change trend and maize yield change in the Songliao Plain maize belt under the $1.5^{\circ} \mathrm{C}$ and the $2.0^{\circ} \mathrm{C}$ global warming scenarios.

\section{Materials and Methods}

\subsection{Study Area and Data}

The Songliao Plain maize belt is located in northeast China at $40^{\circ} 12^{\prime}-46^{\circ} 18^{\prime} \mathrm{N}, 120^{\circ} 42^{\prime}-127^{\circ} 36^{\prime} \mathrm{E}$, including northeast Inner Mongolia, southern Heilongjiang Province, central and western Jilin Province, and most of Liaoning province. The entire area is divided into 17 prefectural regions. The maize belt in the Songliao Plain is surrounded by piedmont diluvial, alluvial plain, and terrace. The plain is flat. The Songliao watershed divides the plain into two parts. North of the watershed is the Songnen Plain, which was formed by flooding of the Songhua River and the Nenjiang River. The middle and the lower reaches of the Liaohe River south of the watershed are called the Liaohe Plain (Figure 1). These provide excellent conditions for maize cultivation in this area. The Songliao Plain maize belt is located in a temperate zone and warm temperate zone with continental and monsoon climate characteristics. Summer is hot and rainy, while winter is cold and dry. Due to the influence of the monsoon climate, $60-65 \%$ of the precipitation in the crop growing season from May to September is concentrated in summer. The average temperature in the growing period for maize is $19-25^{\circ} \mathrm{C}$, the accumulated temperature $\geq 10{ }^{\circ} \mathrm{C}$ is $2800-3200{ }^{\circ} \mathrm{C}$, the precipitation is $300-750 \mathrm{~mm}$, and the frost-free period is 135-155 day.

The meteorological data used in this research were obtained from the National Meteorological Information Center (http://www.resdc.cn/), including monthly mean temperature and precipitation data from 1965 to 2017 at 18 meteorological stations. The yield data were obtained from statistical yearbooks of the Liaoning, Jilin, Heilongiiang, and Inner Mongolia provinces, including the maize yield of each prefecture-level city from 1998 to 2017. The trend yield and the climate yield were calculated by the linear moving average method. The CMIP5 climate model data provided by the Inter-Sectional Impact Model Inter-Comparison Project (ISI-MIP, http:www.isi-mip.org) were used in this study. These data include five climate models from 1850 to 2100, GFDL-ESM2M, IPSL-CM5A-LR, NorESM1-M, MIROC-ESM, and HadGEM2-ES, temperature and precipitation data under four future representative concentration pathways (RCP) scenarios (RCP2.6, RCP4.5, RCP6.0, and RCP8.5), and historical data. Taking 1986-2005 as the reference period, owing to the different resolutions of global climate models, the data of different resolutions were uniformly interpolated to a grid of $0.5^{\circ} \times 0.5^{\circ}$ by bilinear interpolation. 


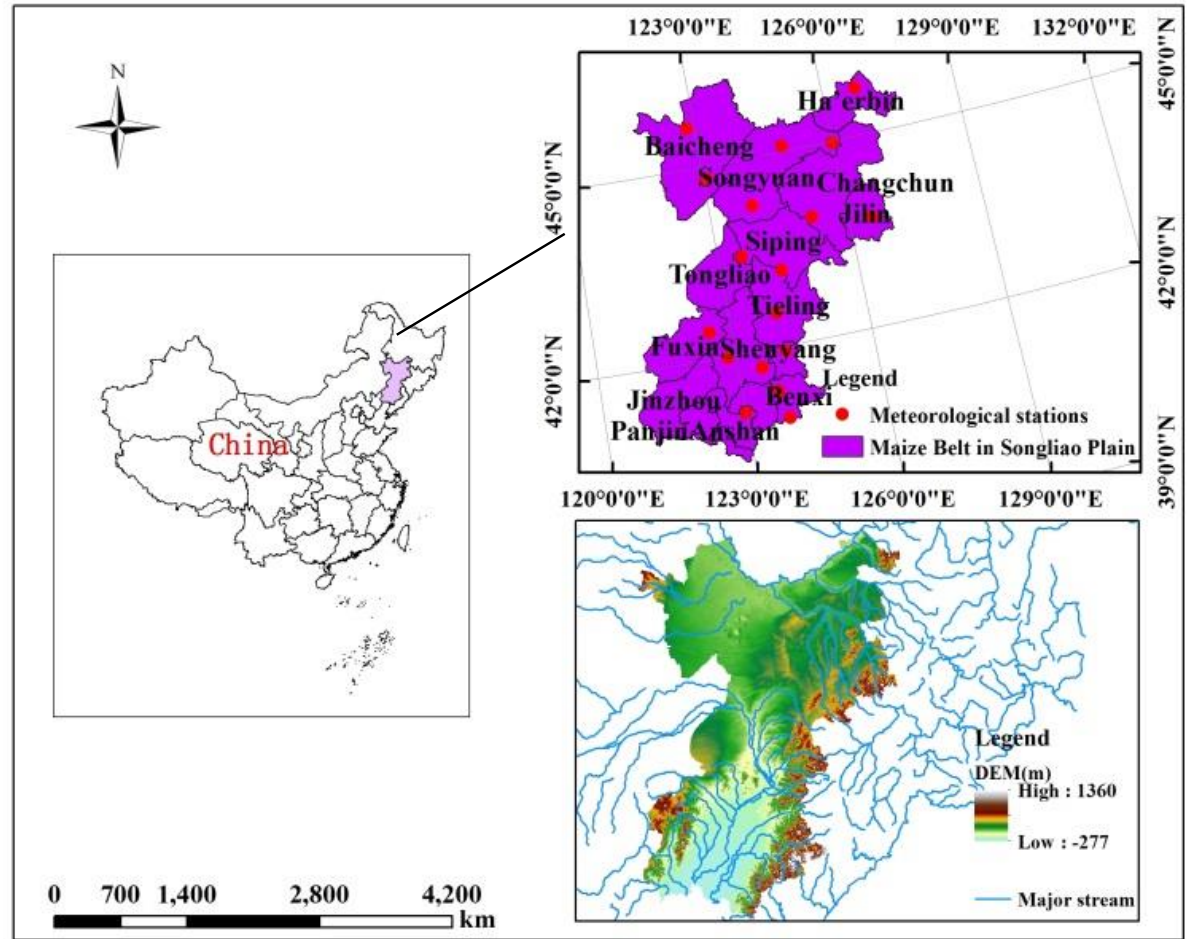

Figure 1. Study area location, meteorological stations, and major river network.

\subsection{Methodology}

\subsubsection{Standardized Precipitation Evapotranspiration Index}

To monitor and study the drought process under the background of global warming, Vicente-Serrano et al. [27] proposed the SPEI. The SPEI index is an ideal index for drought monitoring and assessment under the background of climate warming and is widely used in drought research [28,29]. The specific calculation process is shown in reference [23]. On the basis of referring to the drought conditions recorded in the "China Meteorological Drought Atlas (1956-2009)" over the years in the research area and based on the National Meteorological Drought Grade Standard (GB/T20481-2017) implemented in 2017, this study formulated an SPEI drought grade classification standard (Table 1) suitable for the research area.

Table 1. Classification standard for drought based on the standardized precipitation evapotranspiration index (SPEI).

\begin{tabular}{ccc}
\hline Grade & Type & SPEI Value \\
\hline 1 & Normal & $-0.5<\mathrm{SPEI}$ \\
2 & Light drought & $-1.0<\mathrm{SPEI} \leq-0.5$ \\
3 & Moderate drought & $-1.5<\mathrm{SPEI} \leq-1.0$ \\
4 & Severe drought & $-2.0<\mathrm{SPEI} \leq-1.5$ \\
5 & Extreme drought & SPEI $\leq-2.0$ \\
\hline
\end{tabular}

\subsubsection{Mann-Kendall Mutation Test}

The Mann-Kendall (M-K) mutation test was originally proposed and developed by H.B. Mann [30] and M. G. Kendall [31]. The Mann-Kendall mutation test method is a nonparametric method. It has sample sequences that do not need to follow a certain distribution and are not affected by a few outliers. It is suitable for sequence variables and type variables [32]. The calculation principle of the Mann-Kendall mutation test is as follows. 
Assuming that the time series $x_{1}, x_{2}, \ldots, x_{n}, S_{k}$ represents the cumulative number of sample $X_{i}>X_{j}(1 \leq i \leq j)$ in the $I$ sample, define statistics:

$$
S_{k}=\sum_{i=1}^{k} r_{i}, r_{i}=\left\{\begin{array}{c}
1, x_{i}<x_{j} \\
0, x_{i} \geq x_{j}
\end{array}, j=1,2, \ldots ; k=1,2, \ldots, n\right.
$$

Under the assumption that the time series are randomly independent, the mean and the variance of $S_{k}$ are:

$$
\begin{gathered}
{\left[S_{k}\right]=\frac{K(K-1)}{4}} \\
\operatorname{Var}\left[S_{k}\right]=\frac{K(K-1)(2 K+5)}{72} \quad(a \leq k \leq n)
\end{gathered}
$$

Standardizing $S_{k}$

$$
U F_{k}=\left(S_{k}-\frac{E\left[S_{k}\right]}{\sqrt{\operatorname{Var}\left[S_{k}\right]}}\right)
$$

where $U F_{1}=0$. Given the significance level $\alpha$, if $\left|U F_{k}\right|>U_{\alpha}$, it indicates that the sequence has obvious trend changes, and all $U F_{k}$ can form a curve. This method is applied to an inverse sequence, and the $U B_{k}$ curve is calculated. Given the significance level, such as $\alpha=0.05$, the critical value $U_{0.05}= \pm 1.96$. If the value of $U F_{k}$ or $U B_{k}$ is less than 0 , the sequence shows a downward trend, and if it is greater than 0 , the sequence shows an upward trend. When they exceed the critical line, the downward or the upward trend is significant. The range exceeding the critical line is determined as the time zone where the mutation occurs. If two curves $U F_{k}$ and $U B_{k}$ have intersection points, and the intersection points are between critical lines, the time corresponding to the intersection points is the time when the mutation starts.

\subsubsection{Calculation of Climate Yield and Drought Assessment Indicators}

The influencing factors of agricultural production are mainly divided into climatic factors and social science and technology factors [33]. To study the effect of drought on crop yield, it is necessary to obtain the climate yield. By identifying the long-term trend of yield unit area and using the appropriate de-trend method, the influence of climate on crop yield unit area can be obtained, i.e., the climate yield can be obtained [34].

$$
Y_{c}=Y-Y_{t}
$$

where $Y$ is the actual unit yield, $Y_{t}$ is the trend yield, and $Y_{c}$ is the climate yield, which is the fluctuating yield component affected by climatic factors and can reflect favorable or unfavorable climatic conditions and their effects on the yield year by year.

In this study, the drought frequency was selected as the evaluation index [35]. The drought frequency refers to the ratio of the number of droughts of a certain grade to the total number of years in a statistical period of a certain station. The calculation formula is as follows:

$$
D F=\frac{n}{N} \times 100 \%
$$

where $D F$ is the frequency of drought occurrence, $N$ is the total length of the time series, $n$ is the number of years that SPEI meets a certain level of drought intensity in the statistical period, and the larger DF indicates that drought occurs more frequently.

\subsubsection{Correlation Analysis}

Correlation analysis is a method used to describe the linear correlation of two variables. If there are two data sequences $X=\left\{x_{1}, x_{2}, \ldots \ldots, x_{n}\right\}$ and $Y=\left\{y_{1}, y_{2}, \ldots \ldots, y_{n}\right\}$, the correlation coefficient formula is calculated as follows: 


$$
r=\frac{\operatorname{cov}(x, y)}{S_{x} S_{y}}=\frac{\sum_{i=1}^{n}\left(x_{i}-\bar{x}\right)\left(y_{i}-\bar{y}\right)}{\sqrt{\sum_{i=1}^{n}\left(x_{i}-\bar{x}\right)^{2} \sqrt{\sum_{i=1}^{n}\left(y_{i}-\bar{y}\right)^{2}}}}
$$

where $S_{x}$ and $S_{y}$ are the standard deviations of variables $X$ and $y$, respectively, and $\operatorname{cov}(x, y)$ is the covariance of variables $x$ and $y$. The correlation coefficient $r$ ranges from -1.0 to 1.0. When $r>0$, the two variables are positively correlated, when $r<0$, the two variables are negatively correlated. The larger $|r|$ is, the stronger the correlation between the two variables is.

\section{Results}

\subsection{Analysis of Climate Trend and Drought Index Changes}

\subsubsection{Analysis of the Variation Characteristics of Temperature and Precipitation}

Figure 2a displays the average temperature change trend and the $\mathrm{M}-\mathrm{K}$ mutation test during the growing season in the Songliao Plain maize belt. It can be seen that the temperature in the maize belt of the Songliao Plain shows an overall warming trend in the growing season, with a maximum temperature of $21.65^{\circ} \mathrm{C}(2000)$ and a minimum temperature of $18.64^{\circ} \mathrm{C}(1976)$ and therefore an average temperature of $19.94^{\circ} \mathrm{C}$. The UF and the UB curves crossed around 1995, indicating that a sudden temperature change occurred in 1995. Before this, the increasing temperature trend was not obvious, and after that, there was an obvious warming trend, with the significance level reaching 0.05 . As shown in Figure $2 b$, the precipitation in the maize belt of the Songliao Plain has a downward trend from 1965 to 2017, but the change trend is not obvious, with maximum rainfall of $703.97 \mathrm{~mm}$ in 1994 and minimum rainfall of $318.37 \mathrm{~mm}$ in 2000 and an average of $481.18 \mathrm{~mm}$. The UF and the UB curves frequently crossed before 1985 and crossed around 1995 and 2010 after 1985, which indicates that this is the mutation point of the precipitation change trend in the past 20 years. Moreover, there was a decreasing trend of precipitation after the abrupt change in 1995, but it was not significant.
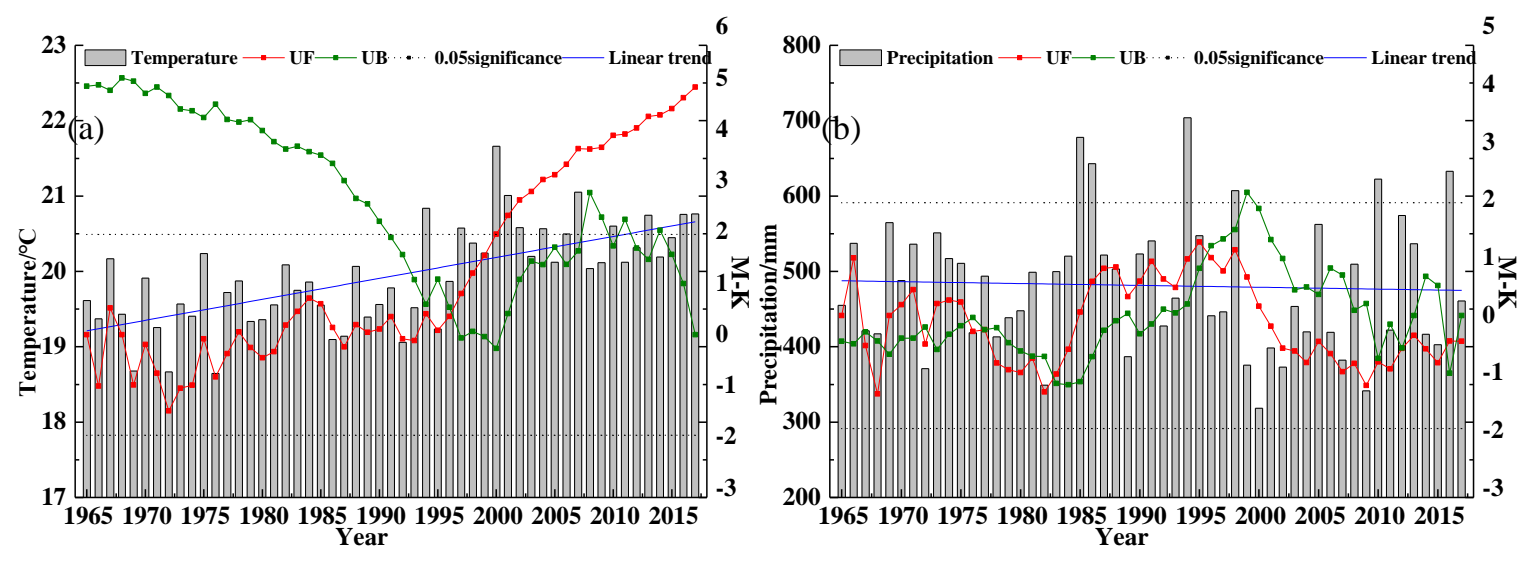

Figure 2. Variation and linear trend of temperature (a) and precipitation (b) in growing season and Mann-Kendall (M-K) mutation test.

As shown in Figure 3a, there is an obvious warming trend in all parts of the Songliao Plain maize belt. The average warming temperature of the whole plain from 1965 to 2017 is $0.28^{\circ} \mathrm{C} / 10 \mathrm{a}$. The warming in most areas is between 0.25 and $0.35^{\circ} \mathrm{C} / 10 \mathrm{a}$. The warming trend is the largest in Liaoyang, southern Songliao Plain maize belt $\left(0.42{ }^{\circ} \mathrm{C} / 10 \mathrm{a}\right)$, and the smallest in Fushun $\left(0.15^{\circ} \mathrm{C} / 10 \mathrm{a}\right)$. Figure $3 \mathrm{~b}$ is a graph showing the spatial variation trend of precipitation in the growing season. The spatial distribution of precipitation is uneven. A total of $60 \%$ of the stations in the maize belt in the Songliao Plain have a decreasing precipitation trend. These areas are concentrated in the south and the northwest of the maize belt in the Songliao Plain, while the northeast of the maize belt in the Songliao Plain has a significant increasing trend of $0-9.4 \mathrm{~mm} / 10 \mathrm{a}$. 


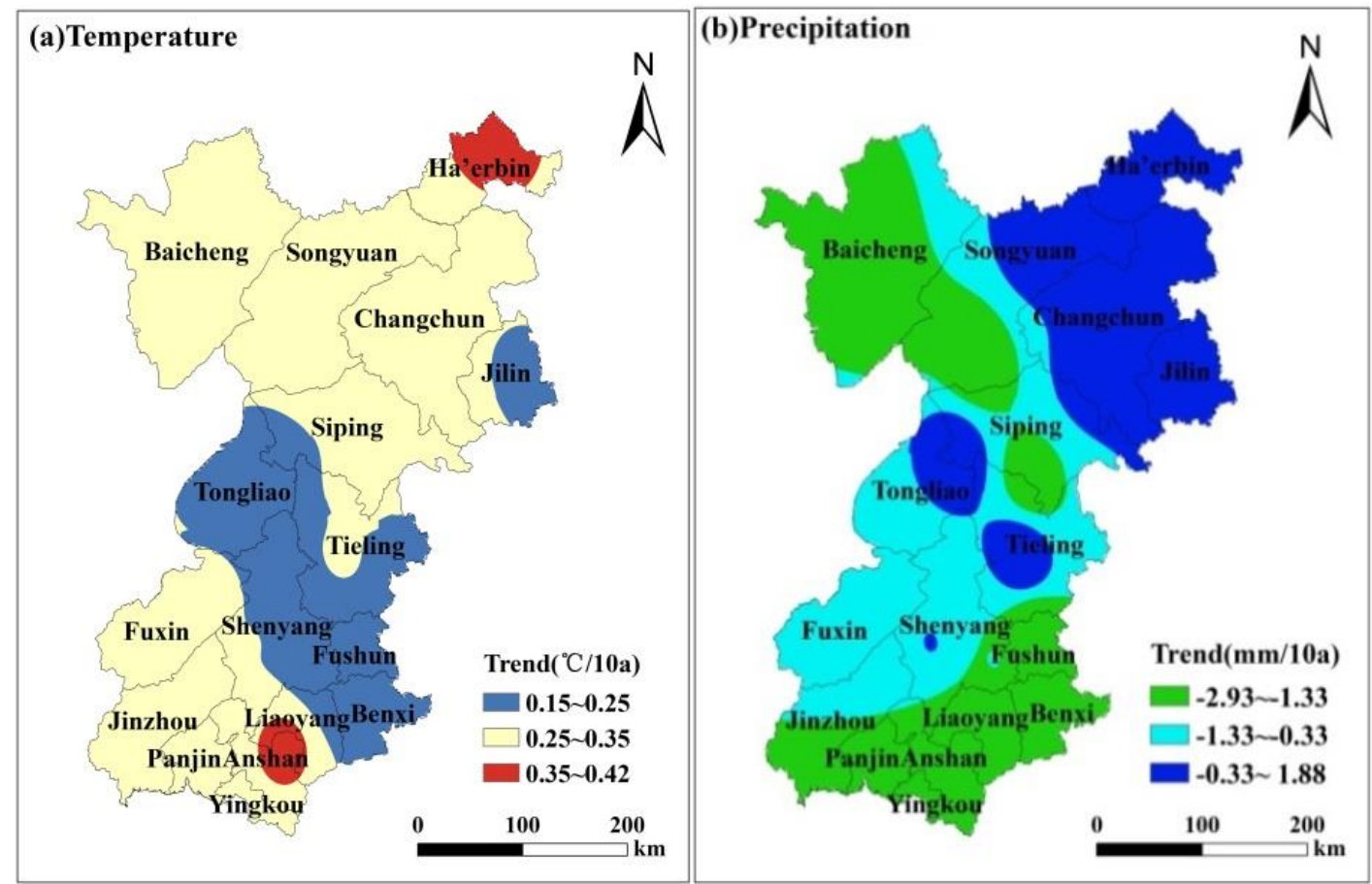

Figure 3. Spatial variation trend of temperature (a) precipitation (b) in the growing season during the period 1965-2017.

\subsubsection{Analysis of Drought Change Characteristics}

The SPEI can describe the succession of drought and flood events at different time scales. Furthermore, in combination with different grades of drought division (Table 1), it can evaluate the characteristics of different types of drought changes at different time scales in the study area. As can be seen from Figure 4, drought and flood events alternate frequently in a short time scale of one and three months, and SPEI- 1 and SPEI-3 are very sensitive to changes in short-term temperature and precipitation (Figure $4 a, b$ ). With the prolongation of the SPEI time scale, the alternate frequency of drought and flood events decreases, showing a longer periodicity. SPEI-6 and SPEI-12 have weak responses to short-term temperature and precipitation, and drought changes are relatively stable. Figure $4 \mathrm{~d}$ shows that maize in the Songliao Plain experiences alternating periods of drought and flooding of about two years, such as 1965-1966 and 1970-1971, with two drought periods of about six years occurring in 1985-1990 and 1998-2003.

The maize growing season generally lasts from May to September. As the September SPEI-6 is calculated by using the temperature and the precipitation sequence of the six months from April to September, which covers the entire growing season, the September SPEI-6 is used to describe the drought situation of the entire growing season. Table 1 is used as the standard for statistical analysis. Figure 5 is a spatial distribution diagram of the frequencies of light, moderate, severe, and extreme drought in the maize belt of the Songliao Plain. The frequency of occurrence from high to low is light drought $>$ moderate drought $>$ severe drought $>$ extreme drought. The frequency of light drought (Figure 5a) is 7.5-24.5\%, with Baicheng and Tieling having the highest frequency and Benxi having the lowest frequency; the frequency of moderate drought (Figure $5 b$ ) is $3.7-17 \%$, and Tieling has the lowest frequency, while Shenyang has the highest frequency; the frequency of severe drought (Figure 5c) is 1.8-9.8\%, and Jilin has the lowest frequency, while Songyuan, Fuxin, Anshan, Yingkou, and other regions have relatively high frequencies; the frequency of extreme drought (Figure $5 \mathrm{~d}$ ) is $0-4 \%$, and Fushun has the highest frequency. Generally speaking, the higher the intensity of drought is, the lower its frequency is. 

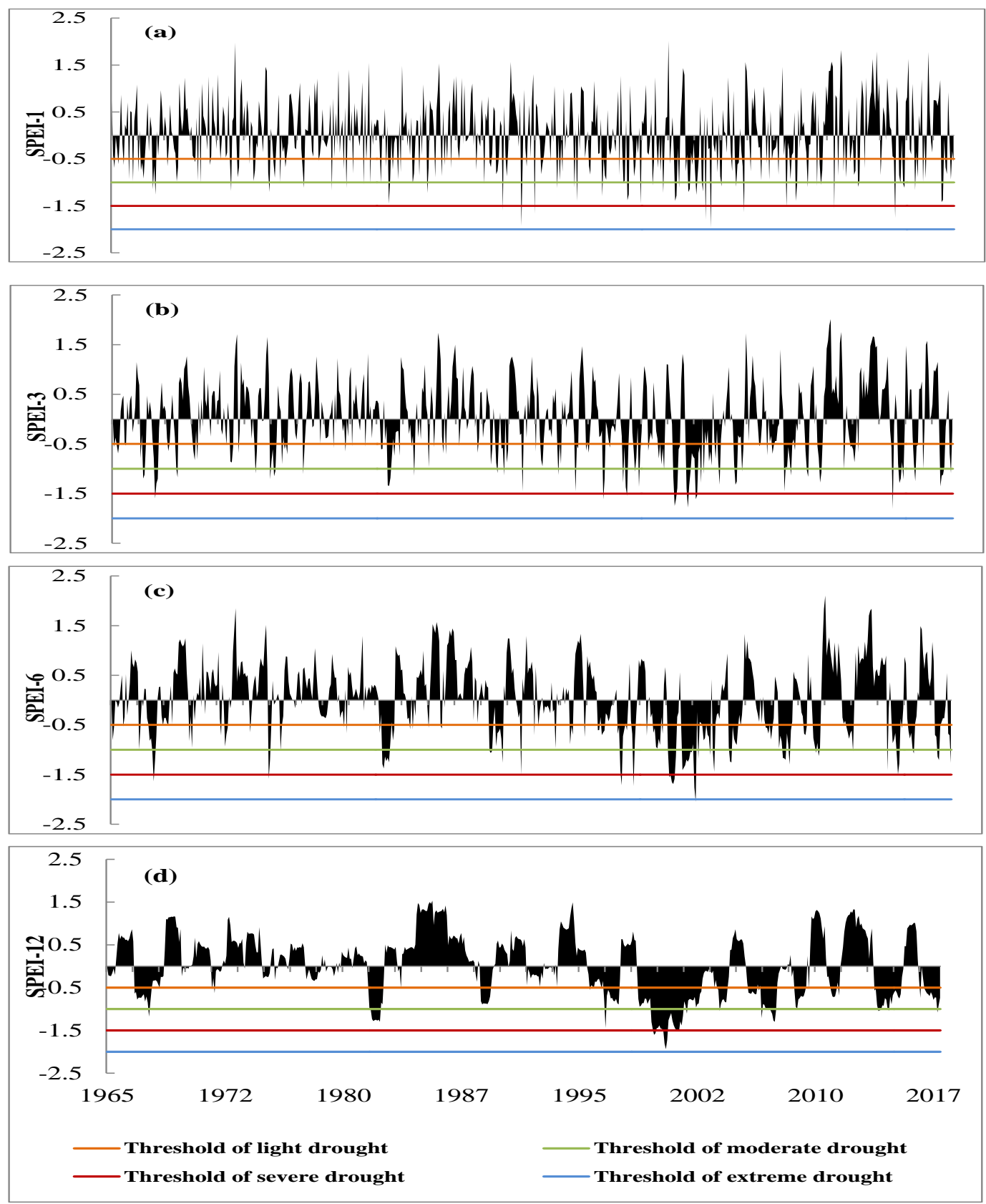

Figure 4. Time series variability of SPEI-1 (a); SPEI-3 (b); SPEI-6 (c); and SPEI-12 (d) in the time period 1965-2017. 

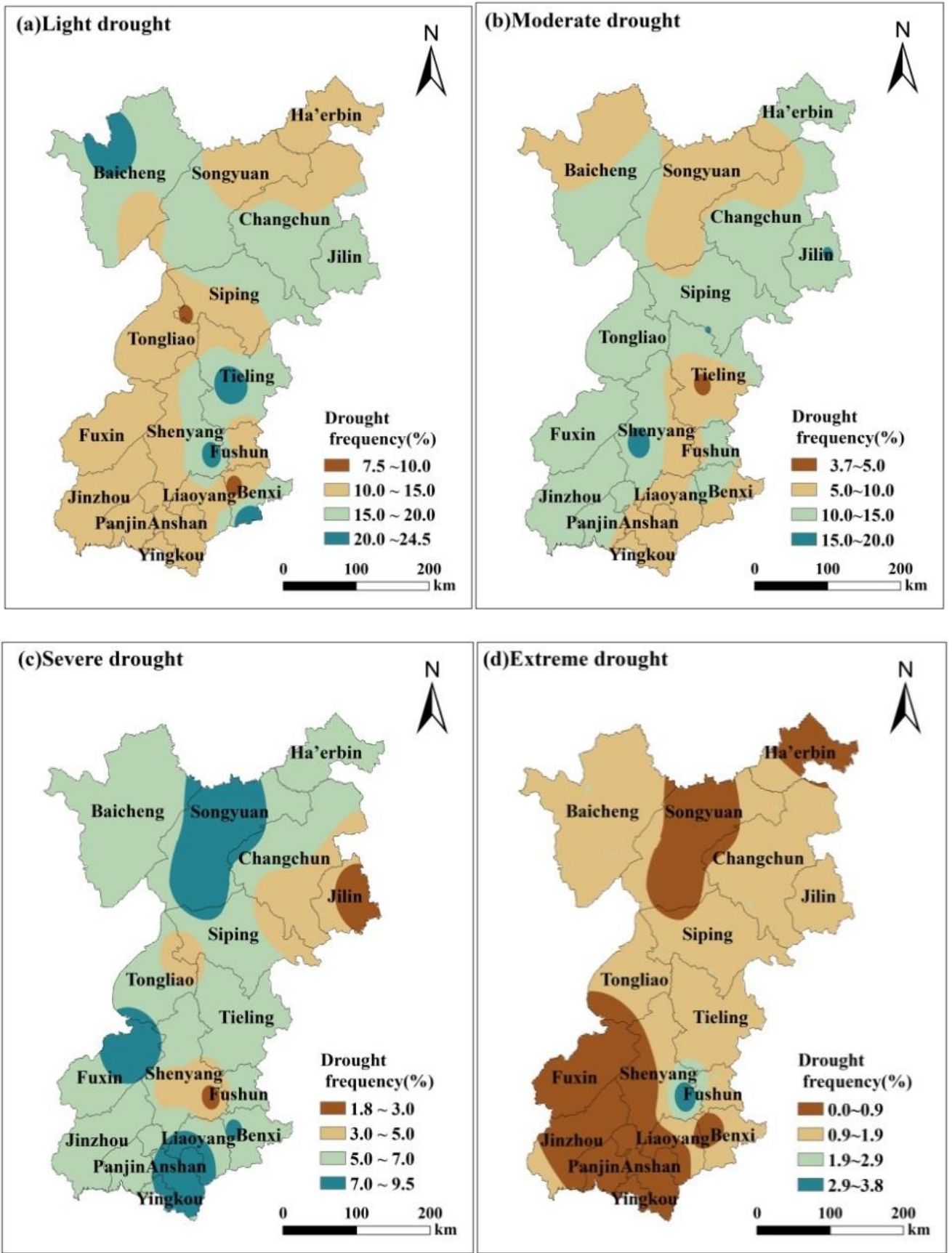

Figure 5. Spatial distribution of the frequencies of light drought (a); moderate drought (b); severe drought (c); and extreme drought (d) during the period 1965-2017.

\subsection{Analysis of the Relationship between Climate Trend, Drought Index, and Yield}

\subsubsection{Analysis of the Maize Yield Changes in the Songliao Plain Maize Belt}

Figure 6a shows the change in the maize yield unit area from 1998 to 2017 in the Songliao Plain maize belt. Of the 17 prefectural regions in the past 20 years, except Baicheng, Fuxin, Jinzhou, Panjin, Shenyang, and Tongliao, there is a trend of production reduction in the other 11 regions. Siping has the largest reduction trend $249(\mathrm{~kg} / \mathrm{ha}) / 10 \mathrm{a}$, followed by Jilin. In 2000, minimum production was achieved in all regions and reached $4929 \mathrm{~kg} / \mathrm{ha}$ in the Songliao Plain. The highest yield of the maize belt in the Songliao Plain was $7643 \mathrm{~kg} / \mathrm{ha}$ in 2008, and the maize yield tended to be stable after 2010. As can be seen from Figure $6 \mathrm{~b}$, the yield distribution in different areas of the Songliao Plain maize belt was also 
different. The average yield of the maize belt in the Songliao Plain is about $6808 \mathrm{~kg} / \mathrm{ha}$. The unit yield in Siping is $9811 \mathrm{~kg} / \mathrm{ha}$, which is twice as high as $4464 \mathrm{~kg} / \mathrm{ha}$ in Tongliao. The unit yield of the central and the northeast regions (Harbin, Songyuan, Changchun, Siping, and Tieling) is higher than that of the northwest and the southeast regions.
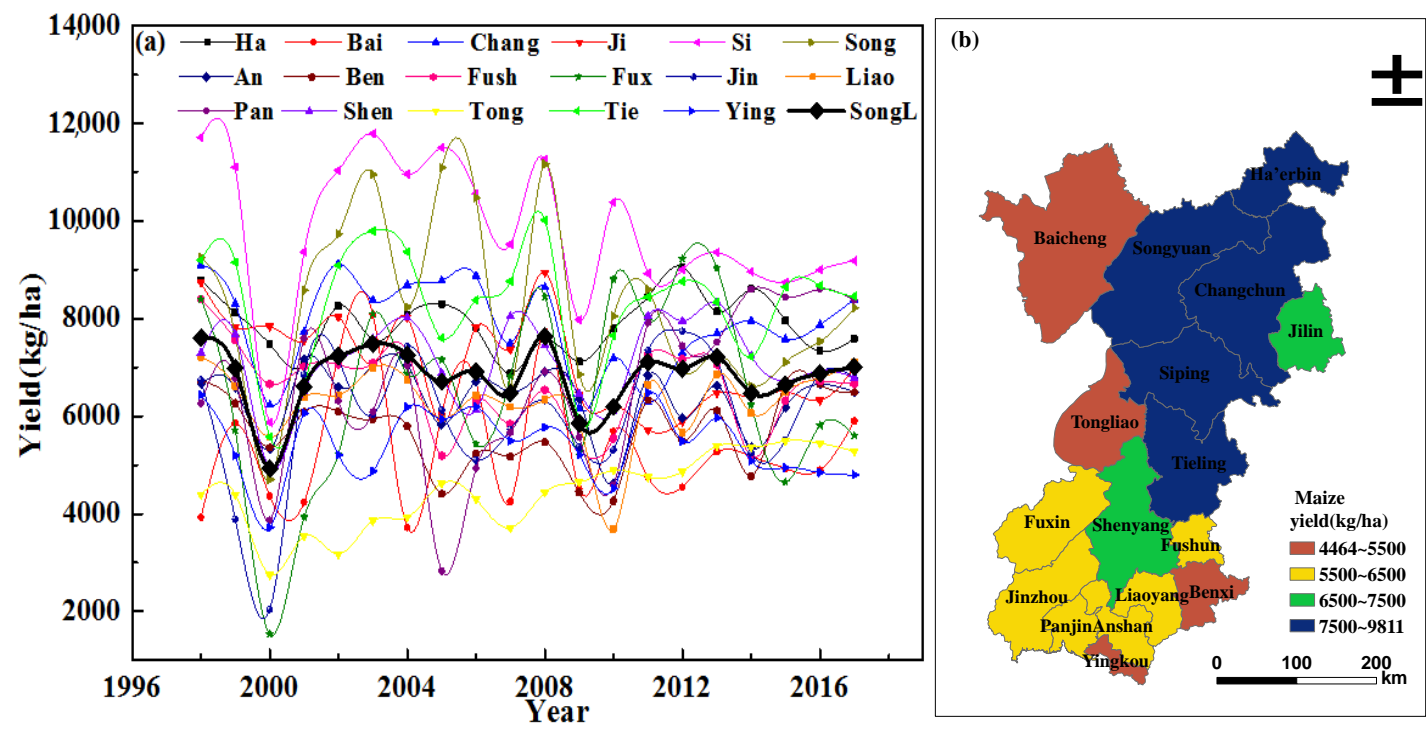

Figure 6. (a) Fluctuation in maize yield and spatial distribution (b) of maize yield in prefectural regions in the Songliao Plain maize belt during the period 1998-2017. Note: Ha'erbin: Ha, Baicheng: Bai, Changchun: Chang, Jilin: Ji, Siping: Si, Songyuan: Song, Anshan: An, Benxi: Ben, Fushun: Fush, Fuxin: Fux, Jinzhou: Jin, Liaoyang: Liao, Panjin: Pan, Shenyang: Shen, Tongliao: Tong, Tieling: Tie, Yingkou: Ying, Songliao: SongL.

\subsubsection{Relationship between Temperature, Precipitation, and Yield}

The calculation results (Table 2) show that the correlation between the climate yield of maize and the temperature in the corresponding growing season (May-September) has varied over the past 20 years in the maize belt of the Songliao Plain, indicating that there are regional differences in temperature sensitivity to different months. Apart from Jilin, Benxi, and Fushun, the temperature in $84 \%$ of the other regions is basically negatively related to the climate yield. Songyuan and Siping have the highest correlations of -0.71 and -0.73 , respectively, $(P \leq 0.01)$, which may be due to the higher warming amplitude in the growth season in these two regions. The correlation between the maize belt and the climate yield in the Songliao Plain is $-0.67(P \leq 0.01)$. All the months of the growing season except May have higher correlations with climate yield. However, relative to each month of the growing season, the mean value (May-September) has a higher correlation with the climate yield. This shows that the mean temperature value in the analysis growth season is a better reflection of the climate yield than the temperature value in each month.

Table 3 shows the correlation between climate yield and precipitation in various regions of the Songliao Plain maize belt in the last 20 years. Except for May, the correlation between climate yield and precipitation is basically positive, but the correlation is lower than that of temperature as a whole. July, the growth season, has the highest relationship with the climatic output of various regions, followed by June. The correlation between the climate yield and the summation of monthly precipitation in the growing season in Siping, Songyuan, and Fuxin is high, i.e., $0.58,0.57$, and 0.71 , respectively $(P \leq 0.01)$, which may be caused by a higher precipitation reduction. The summation of monthly precipitation in the growing season of the maize belt in the Songliao Plain has a significant correlation with climate yield, which is $0.51(P \leq 0.01)$. 
Table 2. Pearson's correlation coefficient of temperature and climate yield in maize growing season in Songliao Plain maize belt during the period $1998-2017$.

\begin{tabular}{|c|c|c|c|c|c|c|c|c|c|c|c|c|c|c|c|c|c|c|}
\hline Month & $\mathrm{Ha}$ & Bai & Chang & Ji & $\overline{\mathrm{Si}}$ & Song & An & Ben & Fush & Fux & Jin & liao & Pan & Shen & Tong & Tie & Ying & SongL \\
\hline May & -0.20 & -0.11 & -0.26 & 0.07 & -0.37 & -0.26 & 0.21 & 0.18 & 0.22 & -0.20 & 0.16 & 0.13 & 0.14 & -0.12 & -0.26 & -0.25 & -0.10 & -0.13 \\
\hline Jun. & -( & -0.44 & & 0.01 & -0.35 & -0.52 ** & -0.39 & -0.20 & -0.17 & -0.21 & -0.32 & $-0.41 *$ & -0.16 & -0.24 & -0.29 & -0.30 & -0.30 & 0.50 * \\
\hline Jul. & -0.02 & & .29 & -0.08 & $-0.41 *$ & 37 & -0.23 & 0.20 & 0. & -0.20 & -0.27 & -0.12 & 0.16 & -0.16 & 0.27 & -0.15 & -0.20 & -0.23 \\
\hline Aug. & -0.20 & -0.18 & -0.35 & -0.24 & -0.51 * & -0.26 & -0.12 & -0.25 & -0.38 & $-0.41 *$ & $-0.45^{*}$ & -0.01 & -0.36 & -0.31 & -0.06 & $-0.43^{*}$ & -0.02 & $-0.47^{*}$ \\
\hline Sep. & -0.22 & -0.20 & 0.19 & 0.15 & -0.08 & -0.28 & -0.25 & 0.23 & 0.11 & -0.13 & -0.12 & -0.03 & -0.12 & -0.15 & -0.07 & 0.09 & -0.33 & -0.12 \\
\hline mean & -0.33 & $-0.48 *$ & $-0.45^{*}$ & -0.02 & $-0.71^{* *}$ & $-0.73^{* *}$ & -0.32 & 0.04 & -0.05 & $-0.45^{*}$ & -0.37 & -0.23 & -0.10 & -0.39 & -0.23 & $-0.45 *$ & -0.40 & $-0.67^{* *}$ \\
\hline
\end{tabular}

Note: ${ }^{*}$ Significant at $P \leq 0.05 ;{ }^{* *}$ significant at $P \leq 0.01$; red and blue indicate positive correlation and negative correlation respectively.

Table 3. Pearson's correlation coefficient of precipitation and climate yield in the maize growing season in Songliao Plain maize belt during the period $1998-2017$.

\begin{tabular}{|c|c|c|c|c|c|c|c|c|c|c|c|c|c|c|c|c|c|c|}
\hline Month & Ha & Bai & Chang & Ji & Si & Song & An & Ben & Fush & Fux & Jin & liao & Pan & Shen & Tong & Tie & Ying & SongL \\
\hline May & -0.09 & 0.04 & 0.04 & -0.23 & 0.13 & 0.14 & -0.29 & -0.24 & -0.41 & 0.18 & -0.02 & -0.30 & -0.12 & -0.11 & 0.35 & 0.08 & -0.10 & -0.03 \\
\hline Jun. & 0.53 * & 0.26 & 0.29 & -0.21 & 0.32 & 0.42 & 0.13 & -0.10 & 0.06 & 0.28 & 0.37 & 0.14 & 0.09 & 0.23 & 0.12 & 0.14 & 0.30 & 0.34 \\
\hline Jul. & 0.01 & 0.15 & 0.33 & 0.10 & $0.57^{*}$ & 0.49 & 0.07 & 0.07 & 0.30 & $0.60^{*}$ & $0.43^{*}$ & -0.14 & -0.15 & 0.25 & 0.06 & $0.41^{*}$ & 0.14 & 0.41 * \\
\hline Aug. & 0.13 & 0.02 & 0.19 & -0.08 & 0.35 & 0.33 & -0.13 & 0.09 & 0.22 & 0.53 * & 0.30 & 0.18 & -0.26 & 0.01 & 0.30 & 0.26 & 0.17 & 0.26 \\
\hline Sep. & 0.17 & -0.04 & 0.13 & 0.32 & 0.16 & 0.14 & 0.03 & -0.06 & 0.05 & $0.48^{*}$ & 0.36 & 0.03 & 0.07 & 0.22 & $0.40^{*}$ & 0.22 & 0.13 & 0.44 * \\
\hline sum & 0.24 & 0.16 & 0.35 & -0.20 & $0.58^{* *}$ & $0.57^{* *}$ & -0.07 & -0.06 & 0.11 & $0.71^{* *}$ & $0.52 *$ & -0.17 & 0.17 & 0.29 & 0.39 & 0.39 & 0.32 & $0.51^{* *}$ \\
\hline
\end{tabular}

Note: * Significant at $P \leq 0.05 ; * *$ significant at $P \leq 0.01$; red and blue indicate positive correlation and negative correlation respectively. 
The results of the regression analysis of the temperature, the precipitation, and the climate yield in the maize belt of the Songliao Plain reveals that the two are in line with those of the multiple linear regression. Among them, the goodness-of-fit $\left(R^{2}\right)$ of the regression equations established for the growth season average temperature, precipitation, and maize yield in $58 \%$ of the areas of the Songliao Plain maize belt is above 0.45 , with the highest significance $(P \leq 0.01)$ being exhibited in Siping $\left(R^{2}=0.66\right)$, followed by the Songliao Plain maize belt $\left(R^{2}=0.54\right)$. The linear regression equation form for the Songliao Plain maize belt is:

$$
y=1.916 x_{1}-782.566 x_{2}+15174.997
$$

where $y$ is the maize climate yield, $x_{1}$ is the precipitation in the growing season, and $x_{2}$ is the average temperature in the growing season. From the regression equation, it can be seen that the maize climate yield in the Songliao Plain maize belt is positively correlated with the precipitation in the growing season and negatively correlated with the average temperature in the growing season.

\subsubsection{Relationship between the SPEI of Different Scales and Yields}

According to previous studies [36], the results of a correlation analysis between the climate yield and the SPEI can reflect the sensitivity of the yield to dry and wet changes at different time scales. The correlation between the climate yield and the SPEI on a short time scale is high, thus SPEI- 1 and SPEI-3 are selected for further analysis. The correlation analysis results between the climate yield and the SPEI-1 in the Songliao Plain maize belt are shown in Table 4. The climate yield of maize is positively correlated with the SPEI-1 in most areas, with the SPEI-1 in July having the highest correlation with the climate yield, especially in Siping, Fuxin, Jinzhou, and Tieling, where the correlation of the Songliao Plain maize belt reaches $0.55(P \leq 0.01)$. The relationship between the average SPEI- 1 in the growing season and the climate yield is $0.72(P \leq 0.01)$ in Fuxin city and $0.68(P \leq 0.01)$ in the Songliao Plain maize belt. This shows that the climate yield decreases with a decrease in SPEI, that is, the drier the weather conditions are, the lower the yield is.

The Pearson correlation between the SPEI-3 in the growth season from 1998 to 2017 and the climate yield in various regions of the Songliao Plain maize belt is shown in Table 5. Except May and June, other growth season months have high correlations with yield, which indicates that the drought sensitive period in most areas is the late growth season. The SPEI-3 in August can better reflect the climate yield. The maize belt in the Songliao Plain, except for Jilin, Anshan, Benxi, Liaoyang, and Panjin, has a positive correlation with SPEI-3. There are two regions (Siping and Fuxin) with correlations of 0.72 and $0.80(P \leq 0.01)$, and the maize belt in the Songliao Plain is $0.64(P \leq 0.01)$. Compared with SPEI-1, SPEI-3 has a stronger correlation with the climate yield of the maize belt in the Songliao Plain.

The middle of June to the middle of August is the jointing to milking stage of maize, while the SPEI-3 in August is the cumulative result of June, July, and August in the growing season, thus the regression result in a specific month gives a better explanation than the average value in the entire growing season. Therefore, the SPEI-3 in August, the growth season with the strongest correlation, was selected for regression analysis with climate yield, and a regression equation was established:

$$
y=556.479 x+114.804
$$

where $y$ is the climate yield of the maize belt in the Songliao Plain, and $x$ is the SPEI-3 in August. Regression results confirmed that the maize climate yield was positively correlated with SPEI-3 in August during the growth season. The $R^{2}$ between the drought index and the climate yield exceeded 0.44 in $52 \%$ of Songliao Plain maize belt; $P \leq 0.01$, and the $R^{2}$ was 0.51 for the established equation. 
Table 4. Pearson's correlation coefficient of SPEI-1 and climate yield in the maize growing season in the Songliao Plain maize belt during the period $1998-2017$.

\begin{tabular}{|c|c|c|c|c|c|c|c|c|c|c|c|c|c|c|c|c|c|c|}
\hline Month & Ha & Bai & Chang & $\mathrm{Ji}$ & $\mathrm{Si}$ & Song & An & Ben & Fush & Fux & Jin & liao & Pan & Shen & Tong & Tie & Ying & SongL \\
\hline May & 0.06 & 0.04 & 0.11 & -0.16 & 0.20 & 0.19 & -0.31 & -0.26 & -0.11 & 0.23 & -0.07 & -0.17 & 0.02 & -0.06 & 0.38 & 0.14 & -0.02 & 0.02 \\
\hline Jun. & 0.58 * & 0.31 & 0.31 & 0.19 & 0.33 & 0.43 * & 0.21 & 0.03 & 0.11 & 0.27 & 0.36 & 0.26 & 0.18 & 0.27 & 0.24 & 0.19 & 0.32 & 0.40 \\
\hline Jul. & 0.07 & 0.22 & 0.43 * & 0.13 & $0.67^{* *}$ & 0.54 * & 0.16 & 0.01 & 0.28 & $0.66^{* *}$ & $0.61^{* *}$ & -0.05 & 0.02 & 0.31 & -0.05 & 0.45 & 0.26 & 0.55 * \\
\hline Aug. & 0.20 & 0.09 & 0.24 & 0.14 & 0.39 & 0.43 * & -0.06 & 0.25 & 0.37 & $0.72 * *$ & 0.36 & -0.06 & -0.01 & 0.13 & 0.37 & 0.39 & 0.14 & 0.38 \\
\hline Sep. & 0.22 & 0.04 & 0.12 & -0.14 & 0.16 & 0.26 & 0.10 & -0.13 & 0.02 & 0.47 & 0.38 & 0.08 & 0.05 & 0.22 & 0.38 & 0.16 & 0.25 & 0.27 \\
\hline mean & 0.45 * & 0.24 & 0.40 * & 0.23 & $0.58^{* *}$ & $0.59^{* *}$ & -0.01 & 0.09 & 0.03 & $0.72^{* *}$ & $0.47^{*}$ & -0.24 & -0.21 & 0.27 & $0.48^{*}$ & $0.43^{*}$ & 0.31 & $0.68^{* *}$ \\
\hline
\end{tabular}

Note: * Significant at $P \leq 0.05 ;{ }^{* *}$ significant at $P \leq 0.01$; red and blue indicate positive correlation and negative correlation respectively.

Table 5. Pearson correlation coefficient of SPEI-3 and climate yield in the maize growing season in the Songliao Plain maize belt during the period $1998-2017$.

\begin{tabular}{|c|c|c|c|c|c|c|c|c|c|c|c|c|c|c|c|c|c|c|}
\hline Month & $\mathrm{Ha}$ & Bai & Chang & Ji & $\mathrm{Si}$ & Song & An & Ben & Fush & Fux & Jin & liao & Pan & Shen & Tong & Tie & Ying & SongL \\
\hline May & -0.08 & 0.15 & -0.02 & -0.18 & 0.17 & 0.14 & -0.39 & 0.19 & -0.34 & 0.20 & -0.20 & -0.20 & -0.36 & -0.12 & 0.08 & 0.06 & -0.13 & -0.14 \\
\hline Jun. & 0.28 & 0.36 & 0.19 & -0.30 & 0.35 & 0.45 & -0.18 & -0.35 & 0.29 & 0.30 & 0.12 & 0.26 & -0.29 & 0.00 & 0.25 & 0.12 & 0.08 & 0.15 \\
\hline Jul. & 0.32 & 0.32 & $0.45^{*}$ & -0.13 & $0.67^{\text {** }}$ & $0.63^{* *}$ & 0.01 & -0.15 & 0.01 & $0.66^{* *}$ & 0.47 & -0.10 & 0.12 & 0.28 & 0.28 & $0.43^{*}$ & 0.27 & 0.49 \\
\hline Aug. & 0.39 & 0.30 & 0.50 * & 0.07 & $0.72^{* *}$ & $0.66^{* *}$ & 0.13 & 0.10 & 0.36 & $0.80^{* *}$ & $0.64^{* *}$ & 0.03 & -0.12 & 0.35 & 0.30 & $0.52^{* *}$ & 0.36 & $0.64^{* *}$ \\
\hline Sep. & 0.18 & 0.15 & 0.38 & -0.07 & 0.58 & 0.50 & 0.07 & 0.09 & 0.32 & $0.77^{* *}$ & $0.58^{* *}$ & -0.05 & 0.15 & 0.28 & 0.27 & $0.47^{*}$ & 0.26 & 0.51 \\
\hline mean & 0.45 & 0.32 & $0.54^{* *}$ & -0.20 & $0.69^{* *}$ & 0.57 & -0.35 & -0.24 & -0.06 & $0.64^{* *}$ & 0.35 & -0.25 & -0.34 & 0.17 & 0.28 & 0.37 & 0.18 & 0.56 \\
\hline
\end{tabular}

Note: ${ }^{*}$ Significant at $P \leq 0.05$; ${ }^{* *}$ significant at $P \leq 0.01$; red and blue indicate positive correlation and negative correlation respectively. 


\subsection{Analysis of Future Climate Trend and Drought Index Changes}

\subsubsection{Determination of the Time Range for $1.5^{\circ} \mathrm{C}$ and $2.0^{\circ} \mathrm{C}$ Global Warming Scenarios}

The Fifth Assessment Report (IPCC.AR5) [3] pointed out that the $1.5^{\circ} \mathrm{C}$ and the $2.0^{\circ} \mathrm{C}$ global warming scenarios are the average temperatures from 1850 to 1900 . However, owing to the limitations of the observation data, 1986-2005 was chosen as the reference period to ensure the quality of data. The average temperature in $1986-2005$ was $0.61^{\circ} \mathrm{C}$ higher than that before the industrial revolution (1850-1900); therefore, it needs to be further increased by $0.89^{\circ} \mathrm{C}$ and $1.39^{\circ} \mathrm{C}$, which gives the global warming scenarios of $1.5^{\circ} \mathrm{C}$ and $2.0^{\circ} \mathrm{C}$.

The time when global warming scenarios of $1.5^{\circ} \mathrm{C}$ and $2.0^{\circ} \mathrm{C}$ were achieved in this study was determined according to the results of different representative concentration pathways (RCPs) driving the global climate model. Eligible data were selected from 20 sets of data combined under five CMIP5 global climate models and four RCP scenarios. The specific calculation scheme for choosing the heating mode of $1.5^{\circ} \mathrm{C}$ and $2.0^{\circ} \mathrm{C}$ was as follows. First of all, the future annual global temperature simulation values were subtracted from their respective simulated mean values from 1986 to 2005 , and then $0.61^{\circ} \mathrm{C}$ was added to obtain the annual global warming values compared with those before industrialization, and the warming sequence was subjected to 20 year moving average processing. For the climate data of global warming of $1.5^{\circ} \mathrm{C}$, according to IPCC.AR5 and the principle of "the early warming reaches $1.5^{\circ} \mathrm{C}$ and the late 21st century temperature control is within $2.0^{\circ} \mathrm{C}^{\prime \prime}$, there were two eligible datasets, namely, IPSL-CM5A-LR, RCP2.6 and GFDL-ESM2M, RCP4.5. Similarly, for the climate data of global warming of $2.0^{\circ} \mathrm{C}$, two sets of data that met the conditions, namely, NorESM1-M, RCP4.5, GFDL-ESM2M, RCP6.0, were selected according to the standard of "the early warming reaches $2.0^{\circ} \mathrm{C}$ and the temperature control at the end of the 21st century is within $2.5^{\circ} \mathrm{C}^{\prime \prime}$. Table 6 shows the basic characteristics of the four sets of selected data.

Table 6. Basic characteristics of the selected global climate model data.

\begin{tabular}{cccccc}
\hline Temperature Rise & Model & Country & $\begin{array}{c}\text { Horizontal } \\
\text { Resolution }\end{array}$ & $\begin{array}{c}\text { Time of } \\
\text { Scenarios } \\
\text { Occurrence of } \\
\text { Temperature Rise }\end{array}$ \\
\hline \multirow{2}{*}{$1.5^{\circ} \mathrm{C}$} & IPSL-CM5A-LR & France & $96 \times 96$ & RCP2.6 & $2021-2040$ year \\
$2.0^{\circ} \mathrm{C}$ & GFDL-ESM2M & The United States & $144 \times 90$ & RCP4.5 & $2042-2061$ year \\
& NorESM1-M & Norway & $144 \times 96$ & RCP4.5 & $2061-2080$ year \\
& GFDL-ESM2M & The United States & $144 \times 90$ & RCP6.0 & $2066-2085$ year \\
\hline
\end{tabular}

RCP: representative concentration pathways.

\subsubsection{Feasibility Analysis of the Climate Model Data}

Multi-model ensemble (MME) is a common method used to evaluate the simulation capability of climate models. It offsets the deviation of each model to a certain extent, is the most similar to the observation results, and is closer to the real natural state [37]. This study uses the unweighted average to calculate MME.

CMIP5 establishes the future prediction results based on the simulation of historical data so that the prediction ability is consistent with the simulation ability. In other words, a better model for simulating historical data and the future results of simulation is also credible. To understand the ability of the CMIP5 model to simulate the historical temperature and the precipitation in the maize belt of the Songliao Plain, this study used three statistics, i.e., of normalized spatial standard deviation (NSTD), Pearson's correlation (PC), and relative root mean error (RRMSE) [38], to judge the similarity between the simulated and the observed data of the model.

According to the SEO-Kyong [39] standard, the model with an NSTD value between 0.75 and 1.25 has better simulation performance. Table 7 shows that the average results of multi-model ensembles with temperatures of $1.5^{\circ} \mathrm{C}$ and $2.0^{\circ} \mathrm{C}$ and precipitation were better than those of a single model. The Pearson's correlations were all at the level of $P \leq 0.01$. Compared with that of temperature, 
the correlation of precipitation was slightly worse, but the simulation performance of the multi-mode ensemble was still higher than that of the single mode. The value of the RRMSE was negative, which indicates that the simulation level of the model was higher than the average level. The greater the negative value is, the better the simulation performance is [40]. It is not difficult to see that the RRMSE averaged by the two multi-mode sets was better than those of other single modes, and the simulation performance of the multi-mode ensemble averaged at $2.0^{\circ} \mathrm{C}$ was better. Therefore, it was feasible to select the multi-mode ensemble average as the research basis for the next step.

Table 7. Normalized spatial standard deviation (NSTD), Pearson's correlation (PC), and relative root mean error (RRMSE) for observed and simulated values.

\begin{tabular}{|c|c|c|c|c|c|c|c|c|c|c|}
\hline \multirow[b]{2}{*}{ Model } & \multicolumn{5}{|c|}{ Temperature } & \multicolumn{5}{|c|}{ Precipitation } \\
\hline & GFDL-ESM2M & IPSL-CM5A-LR & NorESM1-M & $\begin{array}{l}\text { MME } \\
1.5^{\circ} \mathrm{C}\end{array}$ & $\begin{array}{l}\text { MME } \\
2.0^{\circ} \mathrm{C}\end{array}$ & GFDL-ESM2M & IPSL-CM5A-LR & NorESM1-M & $\begin{array}{l}\text { MME } \\
1.5^{\circ} \mathrm{C}\end{array}$ & $\begin{array}{l}\text { MME } \\
2.0^{\circ} \mathrm{C}\end{array}$ \\
\hline NSTD & 0.874 & 1.13 & 1.39 & 0.99 & 0.93 & 1.48 & 0.91 & 1.26 & 0.98 & 1.02 \\
\hline PC & $0.94^{* *}$ & $0.96^{* *}$ & $0.95^{* *}$ & $0.97^{* *}$ & $0.96^{* *}$ & $0.77^{* *}$ & $0.78^{* *}$ & $0.77^{* *}$ & $0.80 * *$ & $0.81 * *$ \\
\hline RRMSE & 0.11 & 0.00 & 0.04 & -0.02 & -0.01 & 0.11 & 0.07 & 0.00 & -0.03 & -0.02 \\
\hline
\end{tabular}

Note: MME1. ${ }^{\circ} \mathrm{C}$ is model IPSL-CM5A-LR and GFDL-ESM2M set average; MME2. ${ }^{\circ} \mathrm{C}$ is model NorESM1-M and GFDL-ESM2M set average. ${ }^{* *}$ Significant at $P \leq 0.01$.

\subsubsection{Changes in Temperature and Precipitation under the $1.5^{\circ} \mathrm{C}$ and the $2.0^{\circ} \mathrm{C}$ Global} Warming Scenarios

The MME1. $5^{\circ} \mathrm{C}$ and the MME2.0 ${ }^{\circ} \mathrm{C}$ were used to predict future temperature and precipitation changes. Under the $1.5^{\circ} \mathrm{C}$ and the $2.0^{\circ} \mathrm{C}$ global warming scenarios, the change trend of temperature and precipitation in the growing season of the Songliao Plain maize belt was significant relative to the reference period (1986-2005). Under these scenarios, most areas of the Songliao Plain maize belt were mainly characterized by temperature and precipitation increase. Under the $1.5^{\circ} \mathrm{C}$ scenario, the average temperature rise was $1.17^{\circ} \mathrm{C}$, and the average temperature rise was $2.14^{\circ} \mathrm{C}$ under the $2.0^{\circ} \mathrm{C}$ scenario; furthermore, the temperature rise amplitudes under both modes were higher than the global average. According to the geographical distribution (Figure $7 \mathrm{a}, \mathrm{b}$ ), the temperature rise at $2.0^{\circ} \mathrm{C}$ was greater than that at $1.5^{\circ} \mathrm{C}$, especially in the northern part of the Songliao Plain maize belt. Under the two scenarios, the temperature changes in the maize belt of the Songliao Plain were less in the south and greater in the north. Under the $1.5^{\circ} \mathrm{C}$ and the $2.0^{\circ} \mathrm{C}$ global warming scenarios, the precipitation in the growing season of the Songliao Plain maize belt increased by $18.9 \mathrm{~mm}$ and $57.9 \mathrm{~mm}$, respectively. From the perspective of spatial distribution (Figure $7 \mathrm{c}, \mathrm{d}$ ), the increase in precipitation gradually decreased from south to north, and the increase under the $2.0^{\circ} \mathrm{C}$ scenario was larger than that under the $1.5^{\circ} \mathrm{C}$ scenario.

\subsubsection{Changes in the Drought Index under the $1.5^{\circ} \mathrm{C}$ and the $2.0^{\circ} \mathrm{C}$ Global Warming Scenarios}

As can be seen from Figure 8, from 2020 to 2100, the SPEI fluctuated between -0.84 (2069) and 0.81 (2044) under the $1.5^{\circ} \mathrm{C}$ scenario, with an average of -0.065 , showing a downward trend at a rate of $-0.031 / 10 \mathrm{a}$, which indicates that the degree of drought in the maize belt of the Songliao Plain would increase. Under the $2.0^{\circ} \mathrm{C}$ global warming scenario, the SPEI mean value of the Songliao Plain maize belt for the period 2020-2100 was -0.0059 , with a maximum of 1.13 (2021) and a minimum of -1.11 (2065). This shows a downward trend at a rate of $-0.061 / 10 \mathrm{a}$, indicating that the drought intensity of the Songliao Plain maize belt was more serious than that under the $1.5^{\circ} \mathrm{C}$ scenario. 

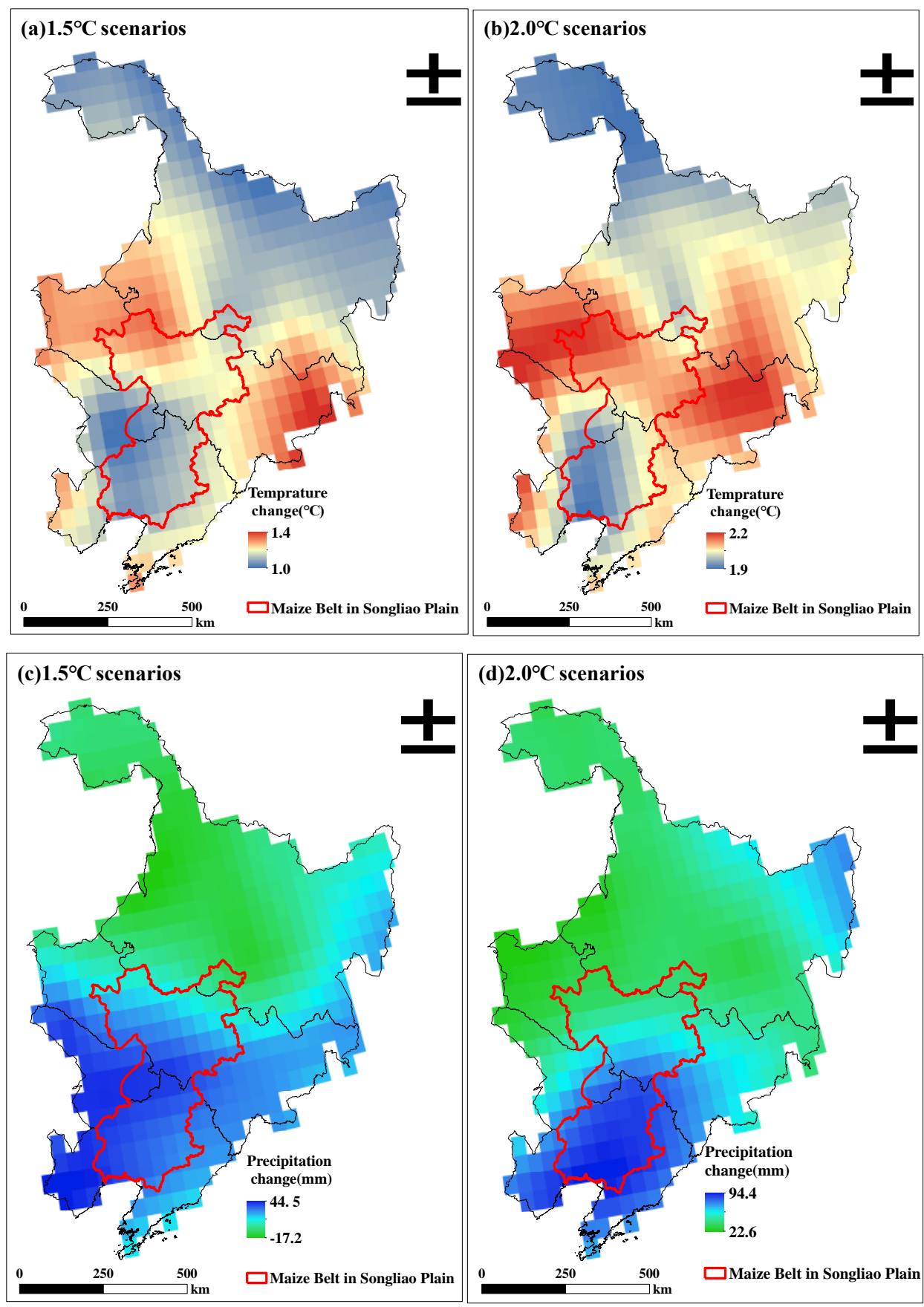

Figure 7. Distributions of temperature and precipitation in the maize growing season relative to 1986-2005 under the $1.5^{\circ} \mathrm{C}(\mathbf{a}, \mathbf{c})$ and the $2.0^{\circ} \mathrm{C}(\mathbf{b}, \mathbf{d})$ global warming scenarios.

In the future, the SPEI of the maize belt in Songliao Plain will decline. The spatial distribution of SPEI-3 is shown in Figure 9 under the $1.5^{\circ} \mathrm{C}$ and the $2.0^{\circ} \mathrm{C}$ global warming scenarios. When the temperature rose to $1.5^{\circ} \mathrm{C}$, SPEI- 3 was between -0.28 and -0.16 compared with the reference period (1986-2005). The regions with smaller changes are located in the northern part of the Songliao Plain maize belt (Baicheng, Songyuan, Siping, Changchun, Jilin and Harbin). The change trend of SPEI-3 gradually increased from north to south, with Liaoyang and Anshan having the largest changes. SPEI-3 changed from -0.35 to -0.26 when the temperature rose to $2.0^{\circ} \mathrm{C}$. The SPEI in the eastern part of the Songliao Plain maize belt (Jilin, Changchun, Siping, Tieling, Fushun) changed little, and the greatest change occurred to the west (Baicheng, Fuxin, Jinzhou, Anshan, Yingkou, Panjin). In general, the SPEI 
at $2.0^{\circ} \mathrm{C}$ had a large variation, about 1.5 times that of $1.5^{\circ} \mathrm{C}$. In other words, the drought in the Songliao Plain maize belt would be more serious under the $2.0^{\circ} \mathrm{C}$ scenario.

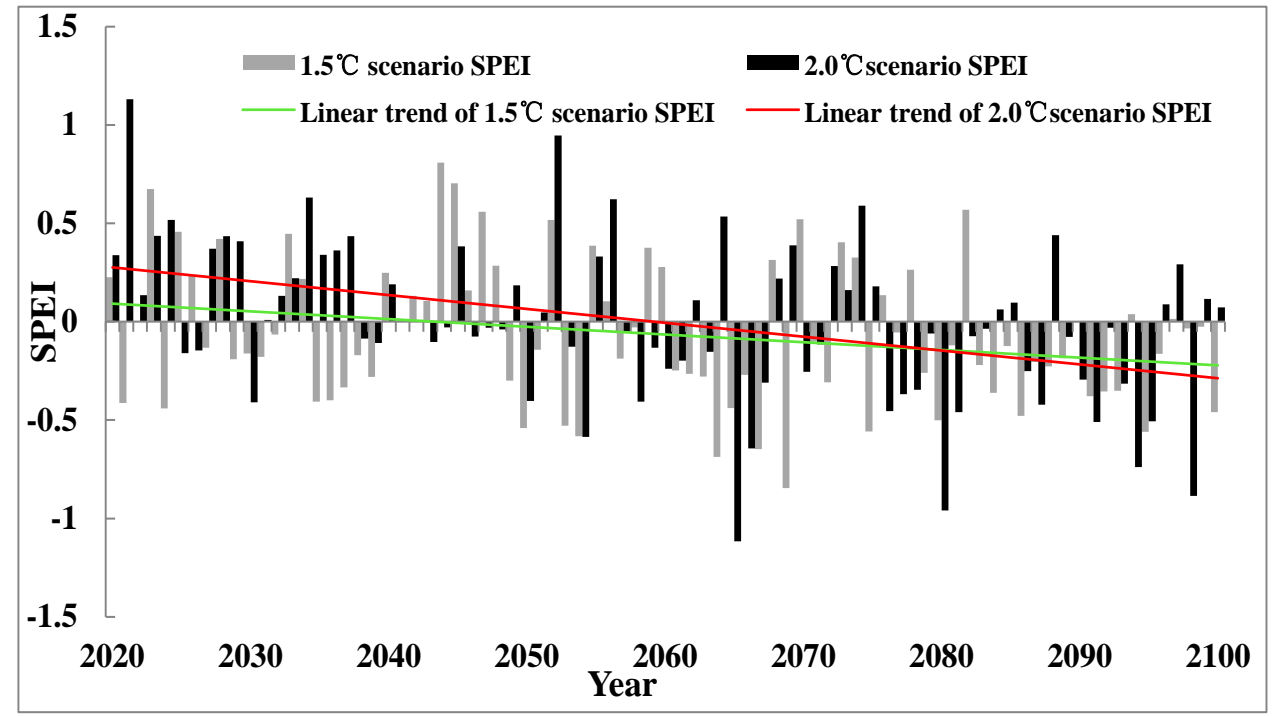

Figure 8. Temporal variation in the annual SPEI in the Songliao Plain maize belt under the $1.5^{\circ} \mathrm{C}$ and the $2.0^{\circ} \mathrm{C}$ global warming scenarios.

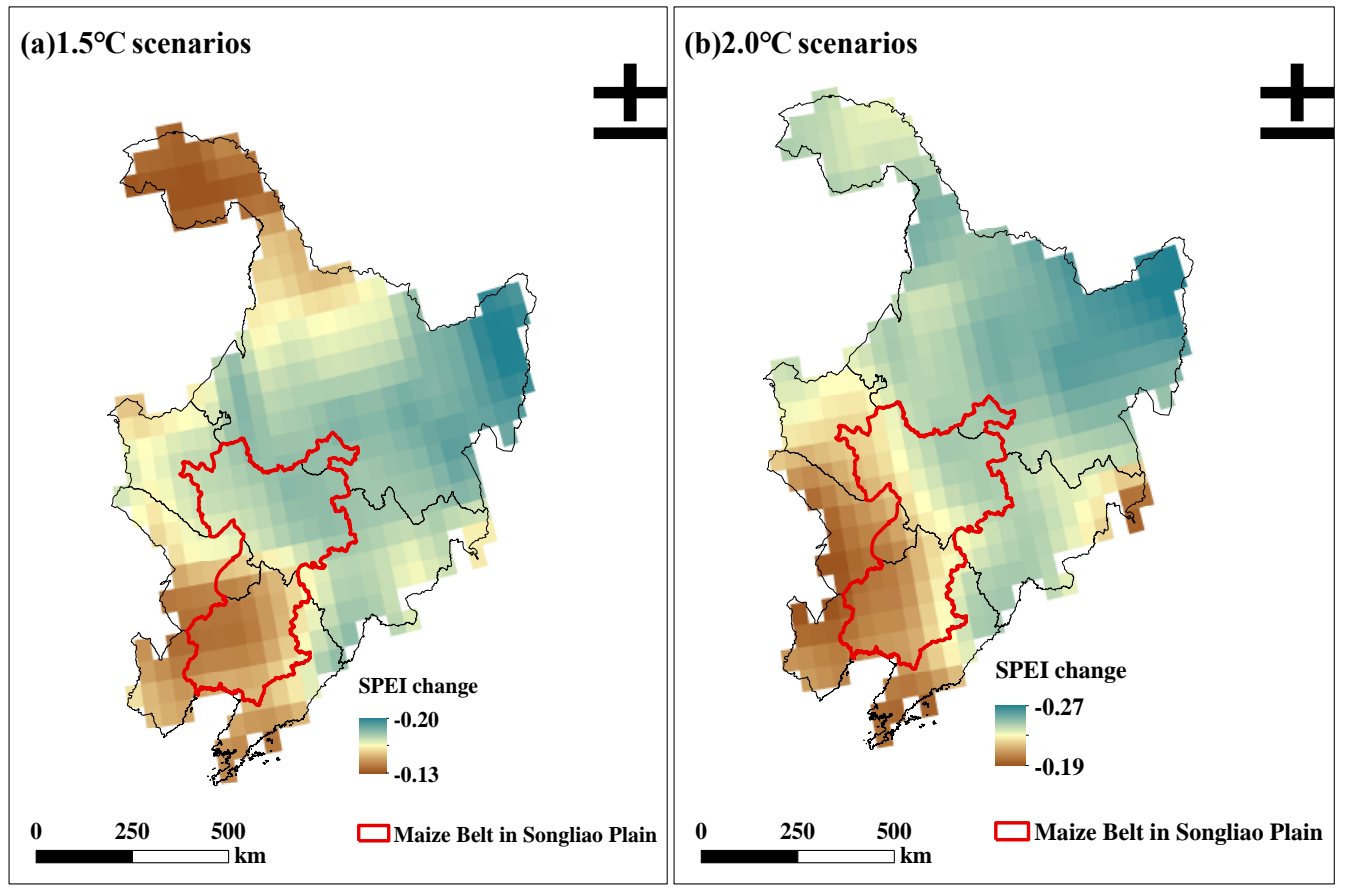

Figure 9. Spatial variation in the SPEI-3 in the Songliao Plain maize belt relative to 1986-2005 under the $1.5^{\circ} \mathrm{C}(\mathbf{a})$ and the $2.0^{\circ} \mathrm{C}(\mathbf{b})$ global warming scenarios.

\subsection{Forecast Analysis of Future Yield}

3.4.1. Climate Yield Prediction of Maize with Temperature and Precipitation Regression Under the $1.5^{\circ} \mathrm{C}$ and the $2.0^{\circ} \mathrm{C}$ Global Warming Scenarios

The average temperature, precipitation, and SPEI-3 accumulation in August in the growing season of the Songliao Plain maize belt simulated by CMIP5 data were substituted into the regression model obtained using historical data, and the results are shown in Figure 10. Figure 10a is the climate yield change in the Songliao Plain maize belt obtained by multiple regression of temperature and 
precipitation under the $1.5^{\circ} \mathrm{C}$ global warming scenario with the rate of change ranging from $6.1 \%$ to $-18.2 \%$. The regions with the largest rate of change are distributed in Siping and the eastern part of Benxi, and the northwest and the northeast parts of Songliao Plain maize belt showed an increasing yield trend. Figure $10 \mathrm{~b}$ shows the climate yield change under the $2.0^{\circ} \mathrm{C}$ global warming scenario. The yield change rate ranged from $5.3 \%$ to $-22.3 \%$, with the largest yield change rate occurring in Panjin and the smallest occurring in Harbin. The yield change rate gradually increased from the northeast to the southwest of the Songliao Plain maize belt, with the northern region showing a trend of increasing production, which was more significant than the $1.5^{\circ} \mathrm{C}$ scenario.

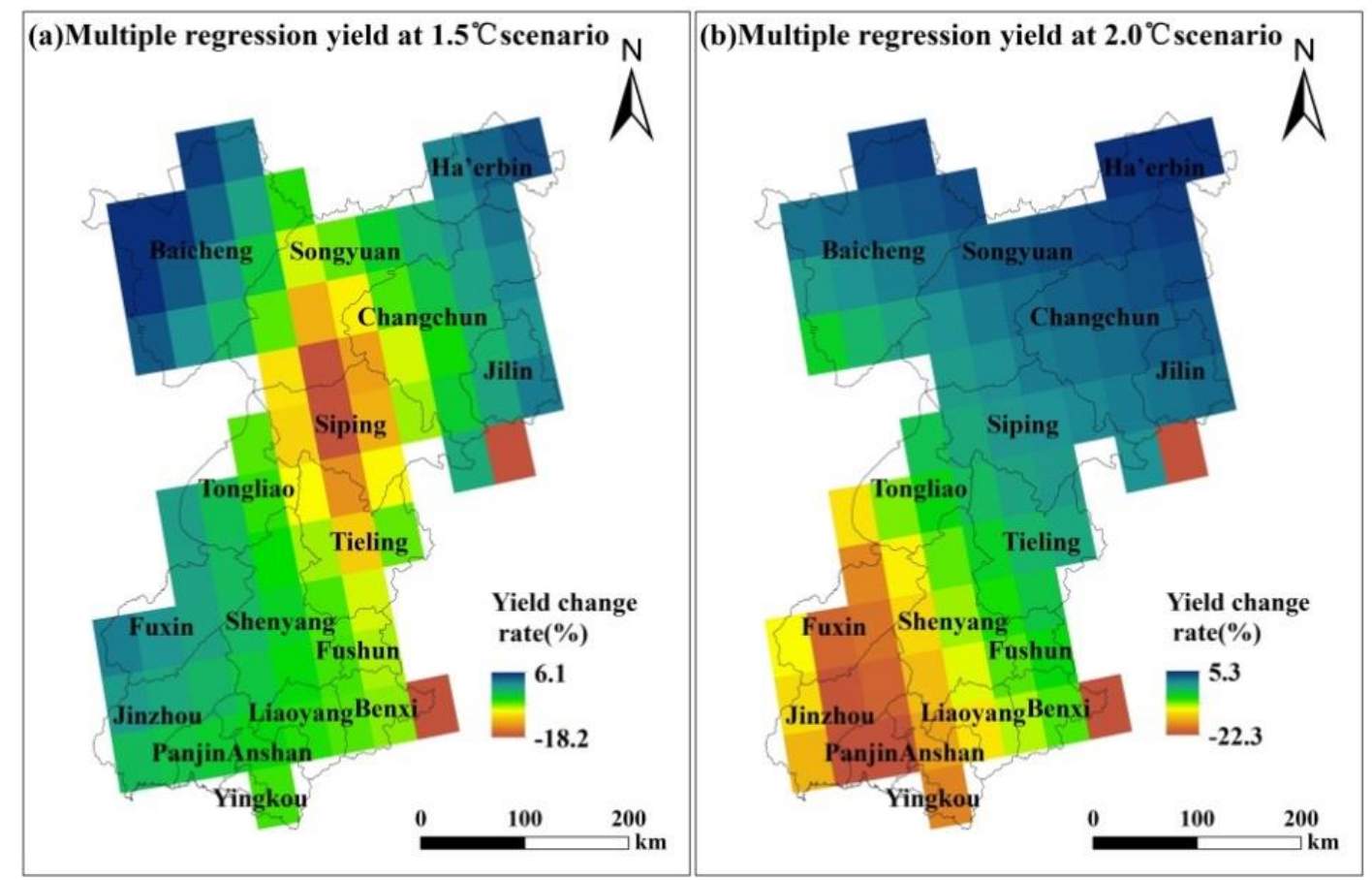

Figure 10. Distribution of the maize yield change in the Songlian Plain maize belt predicted by multiple regression under the $1.5^{\circ} \mathrm{C}(\mathbf{a})$ and the $2.0^{\circ} \mathrm{C}(\mathbf{b})$ global warming scenarios.

3.4.2. Climate Yield Prediction of Maize with Drought Index Regression under the $1.5{ }^{\circ} \mathrm{C}$ and $2.0^{\circ} \mathrm{C}$ Global Warming Scenarios

Figure 11a is the climate yield change obtained by the August SPEI-3 one-variable regression model under the $1.5^{\circ} \mathrm{C}$ global warming scenario. The climate yield change rate ranged from $-5.3 \%$ to $-15.1 \%$. The regions with a high change rate were distributed in the southern part of the maize belt in Songliao Plain, and the climate yield change rate decreased further north. Figure $11 \mathrm{~b}$ shows the climate yield change under the $2.0^{\circ} \mathrm{C}$ global warming scenario. The climate yield change rate was between $-17.5 \%$ and $-29.2 \%$, about twice as high as that of the $1.5{ }^{\circ} \mathrm{C}$ scenario. The yield change rate gradually increased from north to south, and this trend was similar to the spatial pattern of the $1.5^{\circ} \mathrm{C}$ scenario. The overall output was still decreasing, and the yield change rate at $2.0^{\circ} \mathrm{C}$ was stronger than that at $1.5^{\circ} \mathrm{C}$. 


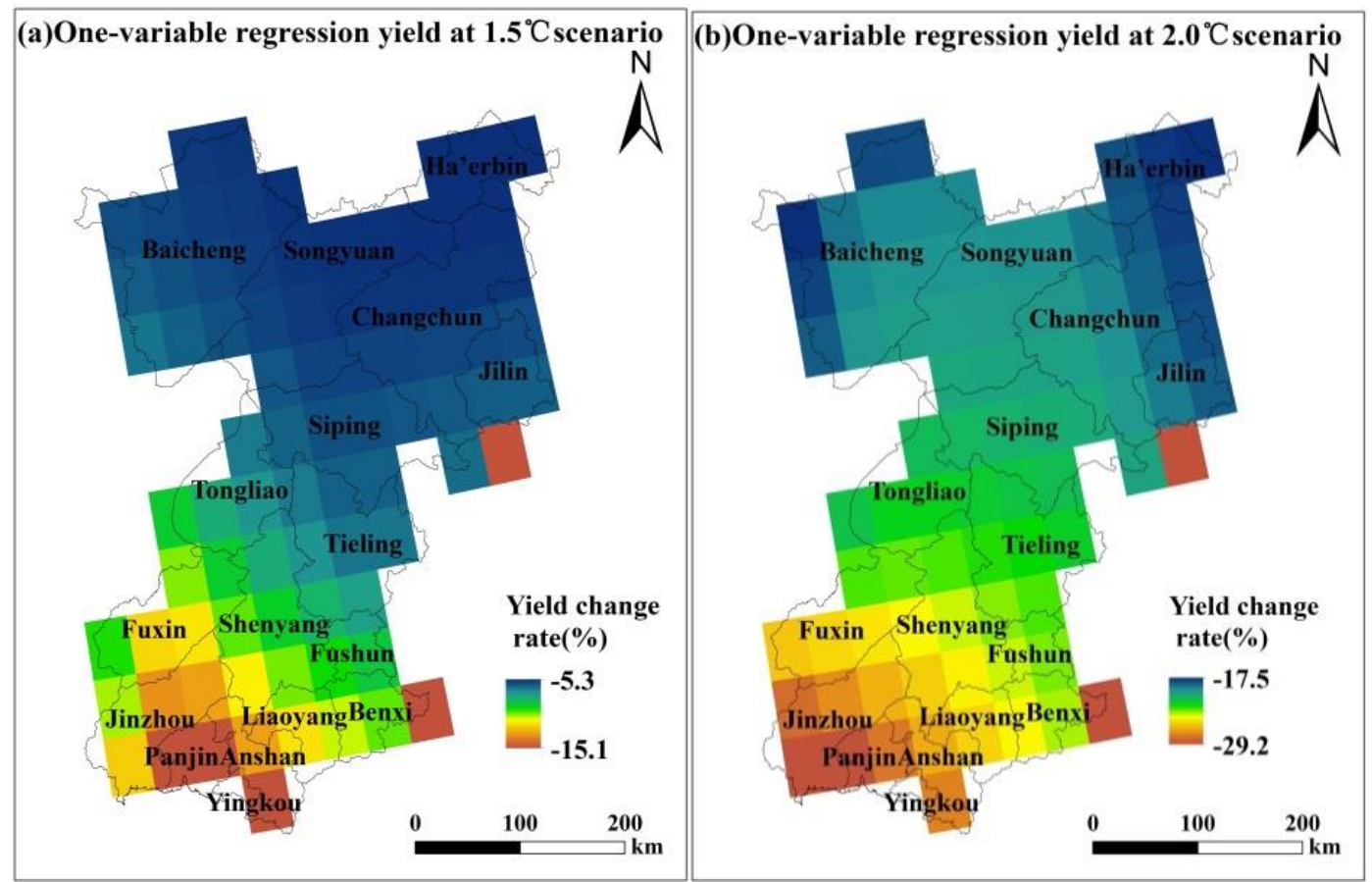

Figure 11. Distribution of the maize yield change in the Songlian Plain maize belt predicted by one-variable regression under the $1.5^{\circ} \mathrm{C}(\mathbf{a})$ and the $2.0{ }^{\circ} \mathrm{C}(\mathbf{b})$ global warming scenarios.

\section{Discussion}

In this study, the maize belt in the Songliao Plain was taken as the research object, and the spatiotemporal changes in climate variables and the drought index during the maize growing season were studied to further establish the relationship between them and the maize climate yield. On this basis, the climate change and the yield under the scenarios of global warming of $1.5^{\circ} \mathrm{C}$ and $2.0^{\circ} \mathrm{C}$ were predicted. The research results could help local government departments to formulate drought and disaster reduction policies and crop spatial layout planning; moreover, the results provide a scientific basis for maize production in the Songliao Plain maize belt to adapt to future climate change. The issues that need to be further studied and discussed in the future include the following:

1. It is worth noting that, in this study, we disregarded the effect of $\mathrm{CO}_{2}$ levels on maize yields because the year-to-year differences in $\mathrm{CO}_{2}$ concentration are too small to generate measurable yield changes [23].

2. The effects of temperature, precipitation, and drought disaster on maize yield have been the main focuses of studies. The growth and the development of maize are very sensitive to temperature and precipitation, and the temperature requirements are different in different growth stages. Excessive or insufficient precipitation also affects the final yield of maize to different degrees. The temperature in the growing season of the Songliao Plain maize belt is negatively correlated with the maize yield. Table 2 shows that the correlation between the climate yield and the growing season temperature of the Songliao Plain maize belt in July and August is higher than that in May and June. This agrees with the findings of Bhatt et al. [41]. Waha et al. [42] found that a decrease in rainfall in the rainy season is very important for maize yield, even exceeding the effect of temperature on maize yield. This study found that the precipitation in the growing season of the maize belt in Songliao Plain has a positive effect on the maize yield, but Hawkins et al.'s [43] study found that the sensitivity of French maize yield to precipitation decreased. Labudova et al. [44] studied the standardized yields of ten crops and their correlations with SPEI and SPI on a one-month, two-month and three-month scale; the results revealed that the highest correlation can be seen between maize yield and three-month scale SPEI in August. This finding is consistent with 
the results of this study. With the continuous development of the economy and technology, the influence of human social activities is increasing. In addition to temperature, precipitation, and dry and wet conditions, there are also different drip irrigation modes [45], mulching conditions [46], planting densities [47], balanced fertilizers such as nitrogen and phosphorus [48], adaptabilities of maize itself to the environment, and crop management methods, which all affect the yield of maize. Therefore, a multi-factor evaluation model that can be used to evaluate climate variables and their impact on yield remains to be constructed.

3. There are many studies on climate change trend prediction and threshold under the background of global warming scenarios of $1.5{ }^{\circ} \mathrm{C}$ and $2.0^{\circ} \mathrm{C}$, but those on its impact on the yield and the physiological processes of major grain crops are still relatively few. In particular, the risks faced by different grain producing areas in China under the background of temperature rises of $1.5^{\circ} \mathrm{C}$ and $2.0^{\circ} \mathrm{C}$ are still in a state of continuous research. As the global academic community has not reached a consensus on how to define the global warming of $1.5^{\circ} \mathrm{C}$ and $2.0^{\circ} \mathrm{C}$, the current climate prediction and impact research on the global warming of $1.5^{\circ} \mathrm{C}$ and $2.0^{\circ} \mathrm{C}$ mostly adopts the multi-mode ensemble average method [49-51] to obtain the warming response under the instantaneous change condition rather than the temperature rise under the stable state expected over the long term. Researchers still need to design a model prediction test specifically for the global warming scenarios of $1.5^{\circ} \mathrm{C}$ and $2.0^{\circ} \mathrm{C}$ to form a special scenario and provide support for impact prediction in different fields.

4. The climate simulation model has uncertainty in setting parameters and estimating greenhouse gas emission physical processes. There are also uncertainties in the social development model and government intervention in greenhouse gas emissions. The combination of these uncertainties magnify the uncertainties that climate change may bring. In this study, five climate models were selected from many CMIP5 models according to the ISI-MIP recommendation. Global warming reached $1.5^{\circ} \mathrm{C}$ and $2.0^{\circ} \mathrm{C}$ during $1986-2005$, which was used as the reference period. Compared with other climate models, the selected model can more effectively support impact assessment in different fields and generate more credible results. Considering the four RCP scenarios and the conditions of stable temperature rises of $1.5^{\circ} \mathrm{C}$ and $2.0^{\circ} \mathrm{C}$ at the end of the 21st century, the time periods and THE data of temperature rises of $1.5^{\circ} \mathrm{C}$ and $2.0^{\circ} \mathrm{C}$ under different model scenarios were selected to minimize the uncertainty of the climate data. This study found that the risk of maize yield reduction in the Songliao Plain maize belt under the background of global warming of $2.0^{\circ} \mathrm{C}$ was significantly higher than that under the $1.5^{\circ} \mathrm{C}$ scenario. Summing up the previous global warming research results, the greater the global warming amplitude is, the greater the comprehensive harmful impact of global warming on maize production will be, which may be due to the large evapotranspiration caused by the increase in the temperature rise amplitude. Although the total precipitation is increasing, the evapotranspiration caused by the warming is more severe. In other words, the excessive warming amplitude offsets the positive impact of the precipitation; therefore, frequent droughts during the maize growing season may affect the maize yield, which may also be the possibility of extreme weather events such as high temperature disasters and heavy rainfall with the $1.5^{\circ} \mathrm{C}$ global warming and the $2.0^{\circ} \mathrm{C}$ global warming scenarios becoming more and more obvious, leading to an increased risk of maize yield reduction.

\section{Conclusions}

In this paper, a relationship between historical meteorological data and yield data was determined. CMIP5 data were used to study the variation characteristics of temperature, precipitation, and drought in the future growth season and then to predict the change in maize climate yield in the Songliao Plain maize belt under the $1.5^{\circ} \mathrm{C}$ and the $2.0^{\circ} \mathrm{C}$ global warming scenarios.

1. The temperature in the growing season of the maize belt in the Songliao Plain had an increasing trend and the precipitation had a decreasing trend from 1965 to 2017. Geographically, Harbin, Liaoyang, and Anshan had the highest temperature rise, while the southeast of the Songliao 
Plain maize belt had the largest precipitation reduction. SPEI- 1 and SPEI-3 in the maize belt of the Songliao Plain were very sensitive to temperature and precipitation and were calculated by using the September SPEI-6. The frequencies of light drought, moderate drought, severe drought, and extreme drought were $16.0 \%, 10.4 \%, 5.8 \%$, and $2.0 \%$, respectively.

2. From 1998 to $2017,65 \%$ of the maize belt in the Songliao Plain showed a trend of yield reduction, with the lowest yield occurring in 2000. The unit yield in the northeast was higher than that in the southwest Songliao Plain maize belt in spatial distribution. From 1998 to 2017, the climate yield was negatively correlated with the temperature in the growing season and positively correlated with the precipitation; furthermore, it was positively correlated with the drought index SPEI-3, and the correlation with SPEI-3 was higher.

3. Under the $1.5^{\circ} \mathrm{C}$ and the $2.0^{\circ} \mathrm{C}$ global warming scenarios, the temperature and the precipitation in the growing season of the maize belt in the Songliao Plain exhibited upward trends relative to the reference period (1986-2005). In the spatial distribution, the temperature increased from south to north, while the precipitation decreased from south to north. These results reveal that, as a whole, drought in the Songliao Plain Maize Belt will be more serious in the future.

4. Under the $1.5^{\circ} \mathrm{C}$ and the $2.0^{\circ} \mathrm{C}$ global warming scenarios, the climate yield changes in the Songliao Plain maize belt predicted by meteorological factor regression were $-7.7 \%$ and $-15.9 \%$, respectively. The climate yield changes obtained by drought index regression were $-12.2 \%$ and $-21.8 \%$, respectively. The more serious the drought is, the more negative its effects on maize yield are.

Author Contributions: All authors contributed meaningfully to this study. A.G. and J.Z. conceived the research topic. S.T., A.H., and Y.B. were responsible for designing the methodology, data acquisition, and analysis. K.L. provided methodology support, and A.G. drafted the manuscript. All authors read and revised the final manuscript.

Funding: This research is supported by the National Science Foundation of China (41571491 and 41877520); the Science and Technology Development Planning of Jilin Province (20190303018SF); and the Science and Technology Planning of Changchun (19SS007).

Acknowledgments: We are most grateful to the National Meteorological Information Center and Compled Model Inter-comparision Project (CMIP5) for kindly providing the climate data and information. The authors are grateful to the many individuals working on the development of free and open-source software for supporting the sharing of knowledge.

Conflicts of Interest: The authors declare no conflicts of interest.

\section{References}

1. Miah, M.G.; Abdullah, H.M.; Jeong, C. Exploring standardized precipitation evapotranspiration index for drought assessment in Bangladesh. Environ. Monit. Assess. 2017, 189, 547. [CrossRef] [PubMed]

2. Solomon, S.; Qin, D.; Manning, M.; Chen, Z.; Marquis, M.; Averyt, K.B.; Tignor, M.; Miller, H.L. Climate Change 2007: The Physical Science Basis. Contribution of Working Group I to the Fourth Assessment Report of the Intergovernmental Panel on Climate Change; Cambridge University Press: Cambridge, NY, USA, 2007.

3. Stocker, T.F.; Dahe, Q.; Plattner, G.K. Climate Change 2013: The Physical Science Basis. Working Group I Contribution to the Fifth Assessment Report of the Intergovernmental Panel on Climate Change; Summary for Policymakers (IPCC, 2013); IPCC: Bern, Switzerland, 2013; pp. 1-33.

4. Lambi, C.; Forbang, T. The economic impact of climate change on agriculture in cameroon. Earth Environ. Sci. 2009, 6, 092017. [CrossRef]

5. Guo, J.P. Advance in impacts of climate change on agricultural production in China. J. Appl. Meteor Sci. 2015, $26,1-11$.

6. Adams, R.M.; Hurd, B.H.; Lenhart, S.; Leary, N. Effects of global climate change on agriculture: On interpretative review. Clim. Res. 1998, 11, 19-30. [CrossRef]

7. Babel, M.S.; Agarwal, A.; Swain, D.K.; Herath, S. Evaluation of climate change impacts and adaptation measures for rice cultivation in Northeast Thailan. Clim. Res. 2011, 46, 137-146. [CrossRef] 
8. Challinor, A.; Watson, J.; Lobell, D.; Howden, S.; Smith, D.; Chhetri, N. A meta-analysis of crop yield under climate change and adaptation. Nat. Clim. Chang. 2014, 4, 287-291. [CrossRef]

9. Sisodia, B.V.S.; Yadav, R.R.; Kumar, S.; Sharma, M.K. Forecasting of pre-harvest crop yield using discriminant function analysis of meteorological parameters. J. Agrometeorol. 2014, 16, 121-125.

10. Brisson, N.; Gate, P.; Gouache, D. Why are wheat yields stagnating in Europe? A comprehensive data analysis for France. Field Crops Res. 2010, 119, 201-212. [CrossRef]

11. Wei, T.; Cherry, T.L.; Glomrod, S.; Zhang, T. Climate change impacts on crop yield: Evidence from China. Sci. Total Environ. 2014, 499, 133-140. [CrossRef]

12. Lobell, D.B.; Schlenker, W.; Costa-Roberts, J. Climate trends and global crop production since 1980. Science 2011, 333, 616-620. [CrossRef]

13. Gupta, R.; Mishra, A. Climate change induced impact and uncertainty of rice yield of agro-ecological zones of India. Agric. Prod. Syst. 2019, 173, 1-11. [CrossRef]

14. Chen, C.; Pang, Y.M.; Pan, X.B.; Zhang, L. Impacts of climate change on cotton yield in china from 1961 to 2010 based on provincial data. Environ. Monit. Assess. 2014, 29, 515-552. [CrossRef]

15. Huang, J.P.; Yu, H.P.; Guan, X.D.; Wang, G.; Guo, R. Accelerated dry land expansion under climate change. Nat. Clim. Chang. 2016, 6, 166. [CrossRef]

16. Peng, S.B.; Huang, J.L.; Sheehy, J.E.; Laza, R.C.; Visperas, R.M.; Zhong, X.; Centeno, G.S.; Khush, G.S.; Cassman, K.G. Rice yields decline with higher night temperature from global warming. Proc. Natl. Acad. Sci. USA 2004, 101, 9971-9975. [CrossRef] [PubMed]

17. Lobell, D.B.; Field, C.B. Global scale climate-crop yield relationships and the impacts of recent warming. Environ. Res. Lett. 2007, 2, 014002. [CrossRef]

18. Chen, Y.; Zhang, Z.; Tao, F. Impacts of climate change and climate extremes on major crops productivity on China at a global warming of $1.5^{\circ} \mathrm{C} \& 2.0^{\circ} \mathrm{C}$. Earth Syst. Dynam. 2018, 9, 543-562.

19. Van Rooy, M.P. A rainfall anomaly index independent of time and space. Notos 1965, 14, 43-48.

20. Palmer, W.C. Meteorological Drought: US Department of Commerce, 3rd ed.; Weather Bureau: Washington, DC, USA, 1965.

21. McKee, T.B.; Doesken, N.J.; Kleist, J.; Anaheim, C.A. The relationship of drought frequency and duration to time scales. In Proceedings of the 8th Conference on Applied Climatology, Boston, MA, USA, 17-22 January 1993.

22. Zhang, Q.; Zhou, X.K.; Xiao, F.J. GB/T20481-2006, Meteorological Drought Level, National Standards of the People's Republic of China; China Standars Publisher: Beijing, China, 2006.

23. Vicente-Serrano, S.M.; Begueria, S.; Lopezmoreno, J.I. A multi-scalar drought index sensitive to global warming: The standardized precipitation evapotranspiration index. J. Clim. 2010, 23, 1696-1718. [CrossRef]

24. Zhang, Q.; Hu, Z. Assessment of drought during maize growing season in Northeast China. Theor. Appl. Climatol. 2018, 133, 1315-1321. [CrossRef]

25. Matiu, M.; Ankerst, D.P.; Menzel, A. Interactions between temperature and drought in global and regional crop yield variability during 1961-2014. PLoS ONE 2017, 12. [CrossRef]

26. Zhang, J.Q. Risk assessment of drought disaster in the maize-growing region of songliao Plain, China. Agric. Ecosyst. Environ. 2004, 102, 133-153. [CrossRef]

27. Vicente-Serrano, S.M.; Cabello, D.; Tomas-Burguera, M.; Martín-Hernández, N.; Beguería, S.; Azorin-Molina, C.; Kenawy, A. Drought variability and land degradation in semiarid regions: Assessment using remote sensing data and drought indices (1982-2011). Remote Sens. 2015, 7, 4391-4423. [CrossRef]

28. Zhang, Q.; Zhang, J.Q. Drought hazard assessment in typical maize cultivated areas of china at present and potential climate change. Nat. Hazards 2016, 81, 1323-1331. [CrossRef]

29. Zhang, Q.; Zhang, J.Q.; Wang, C. Risk assessment of drought disaster in typical area of maize cultivation in China. Theor. Appl. Climatol. 2017, 128, 533-540. [CrossRef]

30. Mann, H.B. Nonparametric tests against trend. Econometrica 1945, 13, 245-259. [CrossRef]

31. Kendall, M.G. Rank Correlation Methods; Hafner: New York, NY, USA, 1962.

32. Xing, L.; Huang, L.; Chi, G.; Yang, L.; Li, C.; Hou, X. A dynamic study of a karst spring based on wavelet analysis and the mann-kendall trend test. Water 2018, 10, 698. [CrossRef]

33. Lobell, D.B.; Asner, G.P. Climate and management contributions to recent trends in U.S. Agricultural Yields. Science 2003, 299, 1032. [CrossRef] 
34. Guo, E.L.; Liu, X.P.; Zhang, J.Q.; Wang, Y.; Wang, C.; Wang, R.; Li, D. Assessing spatiotemporal variation of drought and its impact on maize yield in Northeast China. J. Hydrol. 2017, 553, 231-247. [CrossRef]

35. Mitra, S.; Srivastava, P. Spatiotemporal variability of meteorological droughts in southeastern USA. Nat. Hazards 2017, 86, 1007-1038. [CrossRef]

36. Prabnakorn, S.; Maskey, S.; Suryadi, F.X.; de Fraiture, C. Rice yield in response to climate trends and drought index in the Mun River Basin, Thailand. Sci. Total Environ. 2018, 621, 108-119. [CrossRef]

37. Jiang, L.; Yao, Z.; Huang, H.Q. Climate variability and change on the Mongolian plateau: Historical variation and future predictions. Clim. Res. 2016, 67, 1-14. [CrossRef]

38. Sillmann, J.; Kharin, V.V.; Zhang, X.; Bronaugh, D. Climate extremes indices in the CMIP5 multi model ensemble: Part1. Model evaluation in the present climate. J. Geophys. Res. 2013, 118, 1716-1733.

39. SEO, K.H.; Jung, O. Assessing future change in the East Asian summer monsoon using CMIP3 Models: Results from the best model ensemble. J. Clim. 2013, 26, 1807-1817. [CrossRef]

40. Gleckler, P.J.; Taylor, K.E.; Doutriaux, C. Performance metrics for climate models. J. Geophys. Res. 2008, 113, 1-20. [CrossRef]

41. Bhatt, D.; Maskey, S.; Babel, M.S.; Uhlenbrook, S.; Prasad, K.C. Climate trends and impacts on crop production in the Koshi River Basin of Nepal. Reg. Environ. Chang. 2014, 14, 1291-1301. [CrossRef]

42. Waha, K.; Muller, C.; Rolinki, S. Separate and combined effects of temperature and precipitation change on maize yields in sub-saharan Africa for mid-to late-21st century. Glob. Planet. Chang. 2013, 106, 1-12. [CrossRef]

43. Hawkins, E.; Fricker, T.E.; Challinor, A.J.; Ferro, C.A.; Ho, C.K.; Osborne, T.M. Increasing influence of heat stress on French maize yields from the 1960s to 2030s. Glob. Chang. Biol. 2013, 19, 937-947. [CrossRef]

44. Labudova, L.; Labuda, M.; Takac, J. Comparison of SPI and SPEI applicability for drought impact assessment on crop production in the danubian lowland and the east Slovakian Lowland. Theor. Appl. Climatol. 2017, 128, 491-506. [CrossRef]

45. Zhou, L.; Feng, H.; Zhao, Y.; Qi, Z.; Zhang, T.; He, J.; Dyck, M. Drip irrigation lateral spacing and mulching effects the wetting pattern, shoot-root regulation, and yield of maize in a sand-layered soil. Agric. Water Manag. 2017, 184, 114-123. [CrossRef]

46. Qin, X.L.; Li, Y.Z.; Han, Y.L.; Hu, Y.; Li, Y.; Wen, X.; Liao, Y.; Siddique, K.H. Ridge-Furrow mulching with black plastic film improves maize yield more than white plastic film in dry areas with adequate accumulated temperature. Agric. For. Meteorol. 2018, 262, 206-214. [CrossRef]

47. Wetzel, J.; Stone, A. Yield response of winter squash to irrigation regime and planting density. HortScience 2019, 54, 1190-1198. [CrossRef]

48. Zhang, Y.; Wang, R.; Wang, H.; Wang, S.; Wang, X.; Li, J. Soil water use and crop yield increase under different long-term fertilization practices incorporated with two-year tillage rotations. Agric. Water Manag. 2019, 221, 362-370. [CrossRef]

49. Alfieri, L.; Bisselink, B.; Dottori, F.; Naumann, G.; de Roo, A.; Salamon, P.; Wyser, K.; Feyen, L. Global projections of river flood risk in a warmer world. Earth's Future 2016, 5, 171-182. [CrossRef]

50. Taylor, K.E.; Stouffe, B.J.; Meehl, G.A. An overview of CMIP5 and the experiment design. Bull. Am. Meteorol. Soc. 2012, 93, 485-498. [CrossRef]

51. Zhou, B.T.; Wen, H.Q.Z.; Xu, Y.; Song, L.; Zhang, X. Projected changes in temperature and precipitation extremes in China by the CMIP5 multimodel ensembles. J. Clim. 2014, 27, 6591-6611. [CrossRef]

(C) 2019 by the authors. Licensee MDPI, Basel, Switzerland. This article is an open access article distributed under the terms and conditions of the Creative Commons Attribution (CC BY) license (http://creativecommons.org/licenses/by/4.0/). 